\title{
AP39, a Mitochondria-Targeted Hydrogen Sulfide Donor, Supports Cellular Bioenergetics and Protects against Alzheimer's Disease by Preserving Mitochondrial Function in APP/PS1 Mice and Neurons
}

\author{
Feng-li Zhao,, ${ }^{1}$ Fang Fang, ${ }^{1}$ Pei-feng Qiao, ${ }^{1}$ Ning Yan, ${ }^{2}$ Dan Gao, ${ }^{1}$ and Yong Yan' \\ ${ }^{1}$ Experimental Research Center, Department of Neurology, The First Affiliated Hospital of Chongqing Medical University, \\ Chongqing Medical University, Chongqing 400016, China \\ ${ }^{2}$ Department of Neurology, The University-Town Hospital of Chongqing Medical University, Chongqing 400016, China
}

Correspondence should be addressed to Yong Yan; yanyongzflh@163.com

Received 10 November 2015; Revised 11 December 2015; Accepted 15 December 2015

Academic Editor: David Sebastián

Copyright ( 92016 Feng-li Zhao et al. This is an open access article distributed under the Creative Commons Attribution License, which permits unrestricted use, distribution, and reproduction in any medium, provided the original work is properly cited.

\begin{abstract}
Increasing evidence suggests that mitochondrial functions are altered in $\mathrm{AD}$ and play an important role in $\mathrm{AD}$ pathogenesis. It has been established that $\mathrm{H}_{2} \mathrm{~S}$ homeostasis is balanced in $\mathrm{AD}$. The emerging mitochondrial roles of $\mathrm{H}_{2} \mathrm{~S}$ include antioxidation, antiapoptosis, and the modulation of cellular bioenergetics. Here, using primary neurons from the well-characterized APP/PS1 transgenic mouse model, we studied the effects of AP39 (a newly synthesized mitochondrially targeted $\mathrm{H}_{2} \mathrm{~S}$ donor) on mitochondrial function. AP39 increased intracellular $\mathrm{H}_{2} \mathrm{~S}$ levels, mainly in mitochondrial regions. AP39 exerted dose-dependent effects on mitochondrial activity in APP/PS1 neurons, including increased cellular bioenergy metabolism and cell viability at low concentrations (25-100 $\mathrm{nM})$ and decreased energy production and cell viability at a high concentration (250 nM). Furthermore, AP39 (100 nM) increased ATP levels, protected mitochondrial DNA, and decreased ROS generation. AP39 regulated mitochondrial dynamics, shifting from fission toward fusion. After 6 weeks, AP39 administration to APP/PS1 mice significantly ameliorated their spatial memory deficits in the Morris water maze and NORT and reduced A $\beta$ deposition in their brains. Additionally, AP39 inhibited brain atrophy in APP/PS1 mice. Based on these results, AP39 was proposed as a promising drug candidate for AD treatment, and its anti-AD mechanism may involve protection against mitochondrial damage.
\end{abstract}

\section{Introduction}

Alzheimer's disease (AD) is the most universal age-related neurodegenerative disease and form of dementia, affecting approximately 5.3 million American people. Of those, 5.1 million are over the age of 65 years [1]. AD initially causes memory impairment, and as the disease progresses, patients exhibit motor aberrancies, personality changes, language deficiencies, and other neuropsychiatric symptoms. Because $\mathrm{AD}$ is a complex and multifaceted disease involving various mechanisms, including energy metabolism [2], inflammation, and abnormal cell cycle control [3], the currently available treatments include a combination treatment regimen targeting two or more aspects of $\mathrm{AD}$ pathology [4]. For example, drug treatment for $\mathrm{AD}$ is primarily based on the acetylcholine hypothesis or the amyloid- $\beta(\mathrm{A} \beta)$ accumulation hypothesis, but none of these drugs can stop or reverse the progression of $\mathrm{AD}$.

Swerdlow first proposed the "AD mitochondrial cascade hypothesis" in 2004 [5]. Recently, increasing evidence has shown that mitochondrial dysfunction is a prominent factor in $\mathrm{AD}$ pathogenesis [6], as either a cause or a consequence of $\mathrm{A} \beta$ toxicity. Severe structural and functional abnormalities of the mitochondria were observed in the immediate vicinity of $\mathrm{A} \beta$ plaques [7]. Moreover, $\mathrm{A} \beta$ gradually accumulates within the mitochondria of both living mouse models of $\mathrm{AD}$ and human $\mathrm{AD}$ brain sections, and $\mathrm{A} \beta$ has been found to directly interact with several mitochondrial proteins, for example, 
cyclophilin D (CypD), amyloid- $\beta$ binding alcohol (ABAD) dehydrogenase, and dynamin-related protein 1 (Drpl) [8]. These interactions impair the physiological functions of mitochondria, resulting in limited electron transfer, abnormal adenosine $5^{\prime}$-triphosphate (ATP) production, increased production of reactive oxygen species (ROS), and altered mitochondrial morphology and mobility in AD transgenic models $[9,10]$. Furthermore, a growing body of research suggests that mitochondrial biogenesis is considerably decreased in the brains of both $\mathrm{AD}$ patients and $\mathrm{AD}$ model mice [9, 11-13]. Impaired mitochondrial biogenesis is conducive to mitochondrial dysfunction in $\mathrm{AD}$ [13].

Hydrogen sulfide $\left(\mathrm{H}_{2} \mathrm{~S}\right)$ has recently been recognized as an endogenous gaseous mediator that plays multiple regulatory roles in humans and mammals [14]. Increasing evidence has demonstrated that the dysregulation of $\mathrm{H}_{2} \mathrm{~S}$ homeostasis is implicated in the pathological processes of $\mathrm{AD}$. Recently, our experimental research has revealed that the level of $\mathrm{H}_{2} \mathrm{~S}$ is decreased in $\mathrm{AD}$ patients and that this change in the $\mathrm{H}_{2} \mathrm{~S}$ levels may be related to the severity of $\mathrm{AD}$. The emerging mitochondrial roles of $\mathrm{H}_{2} \mathrm{~S}$ include antioxidant, antiapoptotic, and anti-inflammatory effects [15]. Tang revealed that $\mathrm{H}_{2} \mathrm{~S}$ modulates $\mathrm{A} \beta$-induced damage to $\mathrm{PC} 12$ cells by ameliorating the decrease in the mitochondrial membrane potential (MMP, $\Delta \Psi \mathrm{m})$ and attenuating the increase in intracellular ROS levels [16]. Moreover, Xuan et al. found that $\mathrm{H}_{2} \mathrm{~S}$ may attenuate spatial memory impairment and neuroinflammation within the hippocampus of $\mathrm{AD}$ model mice [17]. With regard to the regulatory role of $\mathrm{H}_{2} \mathrm{~S}$ in cellular bioenergy metabolism, recent studies have shown that $\mathrm{H}_{2} \mathrm{~S}$ can serve as a physiological electron donor and as an inorganic energy source in mammalian cells. Recently, Módis et al. reported that an endogenous intramitochondrial $\mathrm{H}_{2} \mathrm{~S}$-producing pathway, which is governed by 3-mercaptopyruvate sulfurtransferase (3-MST), complements and balances the bioenergetic activity of Krebs cycle-derived electron donors in the Hepalclc7 cell line [18].

Taken together, these findings indicate that the potential effects of $\mathrm{H}_{2} \mathrm{~S}$ on mitochondrial dysfunction in $\mathrm{AD}$ models are significant. Therefore, to clarify whether the new $\mathrm{H}_{2} \mathrm{~S}$ donor AP39, which contains the mitochondria-targeting compound triphenylphosphonium (TPP+) coupled to an $\mathrm{H}_{2} \mathrm{~S}$-donating moiety (dithiolethione) via an aliphatic linker, regulates mitochondrial function and cellular bioenergetics is of great interest. Using APP/PS1 neurons and mice, we first detected the overall viability of the neurons and evaluated the effects of AP39 on cellular bioenergetics and mitochondrial function. In addition, we examined the effects of AP39 on spatial memory deficits and on magnetic resonance imaging (MRI) characteristics of the mouse brains.

\section{Materials and Methods}

2.1. Materials. AP39, a novel mitochondria-targeted $\mathrm{H}_{2} \mathrm{~S}$ donor, was designed and synthesized by Medicilon Inc., as described previously $[19,20]$. Antimycin A, $0.25 \%$ trypsin, 2-deoxyglucose, oligomycin, carbonyl cyanide-4-(trifluoromethoxy)phenylhydrazone (FCCP), trichloroacetic acid, rotenone, 7-azido-4-methylcoumarin (AzMC), monobasic potassium phosphate, dibasic sodium succinate hexahydrate, adenosine $5^{\prime}$-triphosphate (ATP) disodium salt hydrate, fatty acid-free $\mathrm{BSA}$, sodium hydrosulfide hydrate $\left(\mathrm{NaSH} \cdot x \mathrm{H}_{2} \mathrm{O}\right)$, $\mathrm{N}, \mathrm{N}$-diethyl-p-phenylenediamine sulfate, magnesium chloride, and iron(III) chloride $\left(\mathrm{FeCl}_{3}\right)$ were purchased from Sigma-Aldrich Company. The monoclonal anti-A $\beta$ antibody 6E10 was obtained from Covance Inc. (Princeton, NJ, USA). Drp1 was purchased from Novus Biologicals, Inc. Fis1 was purchased from Proteintech Group. Mfn1 and Mfn2 antibodies were purchased from Santa Cruz Biotech, and OPA-1 antibody was purchased from BD Transduction Laboratories. The secondary antibodies goat anti-mouse-HRP and donkey anti-rabbit-HRP antibodies were purchased from GE Healthcare. The Pierce BCA protein assay kit was purchased from Thermo Fisher Scientific (Waltham, MA, USA). Dulbecco's modified Eagle's medium (DMEM), 1\% glutamine, and $1 \%$ penicillin were obtained from Invitrogen. All other chemicals were purchased from Amresco (Solon, $\mathrm{OH}, \mathrm{USA})$.

2.2. Animals and Treatments. This experiment was performed as described previously [21]. All animal protocols were approved by the Animal Research Committee of Chong Qing Medical University. Heterozygous APP/PS1 doubletransgenic mice (APPswe-PS1dE9) were crossed with nontransgenic female mice (the Model Animal Research Center of Nanjing University, Jiangsu, China) to produce hemizygous transgenic mice and nontransgenic littermates. In the double-transgenic mice that coexpressed the Swedish mutation of APP (APPswe) and two FAD-PS1 variants, $A \beta$ plaques accumulated in the brain, and learning and memory ability declined over time [22]. The mice were housed at $23-25^{\circ} \mathrm{C}$ with $60 \%$ humidity under $12: 12 \mathrm{~h}$ light-dark cycles and were provided with free access to food and water throughout the experiment. Pregnant females were sacrificed at gestational days 15-16 (E15-16), and the embryos were removed for the preparation of brain neuronal cultures. The genotyping for APP and PS1 was performed according to the literature to assign cultures to transgenic and nontransgenic groups according to the PCR results with genomic DNA. For the Morris water maze test and the novel object recognition task (NORT), these 12-month-old mice were divided into four groups of fifteen mice in each group: wild-type (WT) mice treated with deionized water or $100 \mathrm{nM} / \mathrm{kg}$ AP39 and AD model mice treated with deionized water or $100 \mathrm{nM} / \mathrm{kg}$ AP39. The mice were treated once daily via intraperitoneal injection for 6 weeks prior to the experiments. After the behavioral tests, the mice were scanned by MRI and then sacrificed for the collection of their blood and brains. The blood was collected into heparinized tubes and then centrifuged at $1000 \mathrm{~g}$ for $10 \mathrm{~min}$ at $4^{\circ} \mathrm{C}$. The plasma (supernatant) was collected to detect $\mathrm{A} \beta_{40}$ and $\mathrm{A} \beta_{42}$ by ELISA. The brains were removed and collected to examine $A \beta$ deposition by immunohistochemistry.

2.3. Primary Neuron Culture. Primary cultures of cortical neurons were generated from the brains of individual embryos at E15-16. Briefly, the brains were removed and then placed in Hank's balanced salt solution at $4^{\circ} \mathrm{C}$. The cortex was dissected from the brain, chopped, and digested 
in $0.25 \%$ trypsin for $16 \mathrm{~min}$ at $37^{\circ} \mathrm{C}$ with gentle shaking. For the mixed neuronal cultures, after cell counting, the dissociated cells were plated at a density of $2 \times 10^{5}$ cells $/ \mathrm{cm}^{2}$ in a $35 \mathrm{~mm}$ dish on poly-d-lysine-coated cover slips in DMEM containing $10 \%$ F-12 and 10\% fetal bovine serum (FBS) and were maintained at $37^{\circ} \mathrm{C}$ in a humidified atmosphere of $95 \%$ air and $5 \% \mathrm{CO}_{2}$. After culturing for $24 \mathrm{~h}$ in vitro, the medium was replaced with serum-free neurobasal medium containing 2\% B27 serum-free supplement, 1\% glutamine, and $1 \%$ penicillin. Thereafter, half of the medium was replaced with neurobasal medium every three days. Pure neuronal cultures were supplemented with glia-conditioned medium (GCM). These neurons were prepared in a similar manner, except that cytosine arabinoside $(5 \mu \mathrm{M})$ was added to the culture media at DIV 4 to block the proliferation of glia, and the cultures were maintained in GCM. After 16 days, the neurons were treated with different concentrations of AP39 diluted in the appropriate medium for $24 \mathrm{~h}$.

\subsection{Measurement of $\mathrm{H}_{2} \mathrm{~S}$ Production}

2.4.1. $\mathrm{H}_{2} \mathrm{~S}$ Production in Neurons and Brain Tissue (Methylene Blue Assay). This experiment was performed based on previous literature $[23,24]$. Neurons were scraped, collected, and then washed 3 times with phosphate-buffered saline (PBS). The neurons were suspended in ice-cold $50 \mathrm{mM}$ Tris$\mathrm{HCl}$ buffer and homogenized by sonication. Homogenized samples were centrifuged at $10,000 \mathrm{~g}$ for $10 \mathrm{~min}$ at $4^{\circ} \mathrm{C}$, and the supernatants were collected as cell lysates. The protein concentrations of the supernatants were determined using the Quick Start Protein Assay Kit.

We used spectrophotometric measurements based on the formation of methylene blue by $\mathrm{H}_{2} \mathrm{~S}$ to detect $\mathrm{H}_{2} \mathrm{~S}$ production. We performed all reactions in duplicate. Cell lysates $(310 \mu \mathrm{L}, 1 \mathrm{mg} / \mathrm{mL})$ in $1.5-\mathrm{mL}$ tubes were mixed with trichloroacetic acid $(20 \% \mathrm{w} / \mathrm{v}, 60 \mu \mathrm{L})$, zinc acetate $(2 \% \mathrm{w} / \mathrm{v}, 30 \mu \mathrm{L})$, and $\mathrm{N}, \mathrm{N}$-dimethyl-p-phenylenediamine sulfate (NNDPD) $(20 \mathrm{mM} ; 40 \mu \mathrm{L})$ in $7.2 \mathrm{M} \mathrm{HCl}$ and $\mathrm{FeCl}_{3}$ $(30 \mathrm{mM} ; 30 \mu \mathrm{L})$ in $1.2 \mathrm{M} \mathrm{HCl}$. The optical absorbance of the resulting solution $(670 \mathrm{~nm}$ ) was measured after 15 min using a 96-well microplate reader (Tecan Systems Inc., Switzerland). $\mathrm{H}_{2} \mathrm{~S}$ was calculated against a calibration curve of $\mathrm{NaHS}$.

To explore the effect of AP39 on the generation of $\mathrm{H}_{2} \mathrm{~S}$ in mice, these 12-month-old WT or APP/PS1 mice were treated with different concentrations of AP39 $(25 \mathrm{nM} / \mathrm{kg}-$ $250 \mathrm{nM} / \mathrm{kg}$ ). The mice were treated once daily via intraperitoneal injection for 6 weeks prior to determining $\mathrm{H}_{2} \mathrm{~S}$ concentration. In brief, mice from each group were anesthetized with chloral hydrate and euthanized by decapitation. Tissues from the hippocampus and cerebral cortex were immediately removed and then homogenized in ice-cold $50 \mathrm{mM}$ potassium phosphate buffer (12\% wt./vol, $\mathrm{pH} 8.0)$ with a Polytron homogenizer. The homogenates were centrifuged at $47,000 \times \mathrm{g}$ for $10 \mathrm{~min}$ at $4^{\circ} \mathrm{C}$ and supernatants were collected. Then the $\mathrm{H}_{2} \mathrm{~S}$ production was measured as above described via methylene blue assay.

2.4.2. $\mathrm{H}_{2} \mathrm{~S}$ Detection in Mitochondria. Neurons were seeded at a density of $5 \times 10^{4}$ cells/well in a Lab-Tek II chamber coverglass system and were maintained at $37^{\circ} \mathrm{C}$ in a humidified atmosphere of $95 \%$ air and $5 \% \mathrm{CO}_{2}$. The $\mathrm{H}_{2} \mathrm{~S}$-sensitive fluorescent dye AzMC was incorporated into a cell-based assay to detect $\mathrm{H}_{2} \mathrm{~S}$ production $[19,25]$. The neurons were loaded with the fluorogenic dyes $10 \mu \mathrm{M}$ AzMC and $200 \mathrm{nM}$ MitoTracker Red CMXRos (Invitrogen) at $37^{\circ} \mathrm{C}$ for $30 \mathrm{~min}$. Different concentrations of AP39 were added to fresh media, and the neurons were further incubated for $2 \mathrm{~h}$, after which $\mathrm{H}_{2} \mathrm{~S}$ imaging was performed. After washing 3 times with PBS, the specific fluorescence from the various dyes was examined using a confocal laser scanning microscope.

2.5. Bioenergetic Analysis in Neurons. We used the XF24 Extracellular Flux Analyzer (Seahorse Bioscience, Billerica, MA, USA) to measure cellular bioenergetic function as previously described [26]. Neurons were treated with different concentrations of AP39 in medium. Neurons were seeded at the optimal density of $3.5 \times 10^{4}$ cells per well and were maintained at $37^{\circ} \mathrm{C}$ in a humidified atmosphere of $95 \%$ air and $5 \% \mathrm{CO}_{2}$. Next, the indices of mitochondrial function were measured according to the following protocol. After recording the basal OCR and PPR levels, oligomycin $(1.5 \mu \mathrm{g} / \mathrm{mL})$ was used to assess the mitochondrial ATP production rate, and FCCP $(0.5 \mu \mathrm{M})$ was used to assess the maximal mitochondrial respiratory capacity (a parameter that characterizes overall mitochondrial function in neurons) via the measurement of the oxygen consumption rate (OCR). Finally, antimycin $\mathrm{A}(2 \mu \mathrm{g} / \mathrm{mL})$ and rotenone $(2 \mu \mathrm{M})$ were used to inhibit the flux of electrons through complexes III and I and to detect the residual nonmitochondrial OCR, which is considered to be mediated by cytosolic oxidase enzymes. Bioenergetic parameters were normalized to the neuron count, as the same number of neurons was seeded in each well.

2.6. MTT Assay. Cell viability was determined by the MTT reduction assay method as follows. The neurons were cultured and treated with different concentration of AP39 for $24 \mathrm{~h}$ in 96-well plates. MTT was added to each well with a final concentration of $0.5 \mathrm{mg} / \mathrm{mL}$ for $4 \mathrm{~h}$. After a 4 -h incubation at $37^{\circ} \mathrm{C}$, the MTT solution was removed and the insoluble formazan crystal was dissolved in DMSO. The absorbance of the colored solution was measured at $570 \mathrm{~nm}$ using a microplate reader (Tecan, USA).

2.7. LDH Assay. Lactate dehydrogenase (LDH) release, an indirect measurement of cell death, was determined using a cytotoxicity assay according to the manufacturer's instructions. Briefly, $30 \mu \mathrm{L}$ of supernatant was saved before the addition of MTT and mixed with $100 \mu \mathrm{L}$ of freshly prepared $\mathrm{LDH}$ assay reagent. $\mathrm{LDH}$ release into the culture medium was detected using a colorimetric reaction reading of absorbance at $490 \mathrm{~nm}$ according to manufacturer's protocol for the $\mathrm{LDH}$ assay kit (Beyotime, Jiangsu, China). LDH activity values are shown as $V_{\max }$ for kinetic assays in $\mathrm{mOD} / \mathrm{min}$.

2.8. Cellular ATP Measurements. Neurons were plated at a density of $0.5 \times 10^{4}$ cells/well in 96-well plates before the experiment. WT and APP/PS1 neurons were treated with 
water or 100 nMAP39, and the samples were measured in triplicate. After incubation for $24 \mathrm{~h}$, the ATP levels were assessed using the ATP Bioluminescent Assay Kit (Sigma-Aldrich). The fluorescence intensity, which was linearly related to the ATP concentration, was measured using a microplate luminometer [27].

\subsection{Measurement of Mitochondrial and Nuclear DNA} Integrity. DNA integrity was assessed using gene-specific semiquantitative PCR assays as described previously [28]. Briefly, total DNA from experimental neurons was isolated using the DNase Blood and Tissue Kit. Quantification of a PCR-amplified 9-kb nuclear-specific DNA fragment using PicoGreen fluorescent dye to measure double-stranded DNA was used to estimate damage to nuclear DNA. Quantification of a PCR-amplified 10-kb mitochondrial-specific DNA fragment using PicoGreen dye was used to detect damage to mitochondrial DNA. The obtained data were normalized by the PCR amplification of a 117-bp mitochondrial genomespecific fragment to correct for multiple copies of the mitochondrial genome. Preliminary assays were performed to ensure the linearity of PCR amplification with respect to the number of cycles and DNA concentration.

2.10. Measurement of Intracellular ROS. The fluorescent dye $2^{\prime}, 7^{\prime}$-dichlorofluorescein diacetate (DCFH-DA) was used to assess the intracellular production of ROS according to the manufacturer's instructions. Following the indicated treatment, the neurons were harvested, washed twice with PBS, and centrifuged at $1000 \mathrm{~g}$ for $10 \mathrm{~min}$. Then, the cells were resuspended in $10 \mu \mathrm{M}$ DCFH-DA (Beyotime, Jiangsu, China) solution and incubated in a $\mathrm{CO}_{2}$ incubator at $37^{\circ} \mathrm{C}$ for $30 \mathrm{~min}$ in the dark, followed by three washes with PBS. Finally, the cells were resuspended in $0.5 \mathrm{~mL}$ of PBS, and the fluorescence intensity of the samples was analyzed by flow cytometry.

2.11. Western Blot. Approximately $1 \times 10^{7}$ neurons were collected for each experiment. The cell samples were lysed with Western and IP lysis buffer (Beyotime, Jiangsu, China) and centrifuged at $12,000 \mathrm{~g}$ for $15 \mathrm{~min}$. The protein concentrations were determined using the BCA protein assay kit. A total of $20 \mu \mathrm{g}$ protein was loaded per lane and subjected to electrophoretic separation in a $10 \%$ SDS-PAGE gel. After separation, the proteins were electrically transferred to a nitrocellulose transfer membrane (PerkinElmer Life Sciences) for $1 \mathrm{~h}$. After blocking with 5\% nonfat milk in Trisbuffered saline containing Tween-20 (TBST), the membranes were incubated in primary antibodies against Mitofusin-1 (Mfn-1,1:200, rabbit polyclonal), Mitofusin-1 (Mfn-2, 1:200, rabbit polyclonal), Optic Atrophy-1 (OPA-1, 1:400, mouse monoclonal), Fission-1 (Fis-1, 1:1500, rabbit polyclonal), Drp-1 (1:200, rabbit polyclonal), or VDAC $(1: 500$ to $1: 1000)$ overnight at $4^{\circ} \mathrm{C}$. The membranes were subsequently incubated in donkey anti-rabbit or goat anti-mouse antibodies for $1 \mathrm{~h}$ at $37^{\circ} \mathrm{C}$. Chemiluminescent detection was performed using the Pierce ECL Western blotting substrate, and the signals were analyzed using Quantity One software.

\subsection{Behavioral Testing}

2.12.1. Morris Water Maze Test. The Morris water maze test was performed according to the protocols of a previous study [29]. Animals were randomly assigned to different treatment groups and then were pretreated with once-daily administration of either water or AP39 for 6 weeks prior to testing. Briefly, the mice were put into each quadrant in a random order to locate a hidden platform within $1 \mathrm{~min}$, and the experimenter would guide them to the platform if the mice failed to find the platform. Then, the mice were left on the platform for $30 \mathrm{~s}$ to help them remember the platform location. The mice were trained to locate the platform using a two-trial-per-day regimen, and the training was divided into two blocks of four trials. The first block of four trials was performed in the morning, and the second block of four trials was performed in the afternoon. In the probe trial, the platform was removed, and the mice were placed in the water for a single 60 -s period. The latency to reach the platform was recorded for both the training and probe trials, and the parameters were analyzed using an EthoVision 3.1 analysis system by an observer who was blinded to the treatment status of the mice.

2.12.2. Novel Object Recognition Task (NORT). The novel object recognition task (NORT), which is based on the natural instinct of rodents to interact more with a novel object than a familiar object, was performed to assess the memory of the experimental mice as described in the literature [30]. Briefly, on the first day of acclimation, each mouse was provided with $10 \mathrm{~min}$ to interact with either object for combined $30 \mathrm{~s}$. The total distance traveled was recorded and analyzed to evaluate the motor ability of the mice. On the following day, the mice were exposed to two identical objects (A1 and A2) for $10 \mathrm{~min}$ for familiarization. Both objects A1 and A2 had identical textures, colors, and sizes and were positioned in two adjacent corners from the walls. After a 24$\mathrm{h}$ delay in the mice cages, the mice were again placed into the same arena used before for $10 \mathrm{~min}$ and then exposed to the field for $5 \mathrm{~min}$ in the presence of the old familiar (A1) and a new different novel (B) object. We determined the amount of time spent at both familiar and novel objects through video analysis using a "within object area" scoring method. A mouse was scored as interacting with the object when its nose was in contact with the object or directed at the object within $\leq 2 \mathrm{~cm}$. Time spent standing, sitting, or leaning on the secured object was not scored. The exploratory preference was defined as the percentage of total time that the animal spent investigating the novel object and calculated for each animal by the following ratio: $\mathrm{TB} /(\mathrm{TA}+\mathrm{TB}) \times 100 \%$ [TA: time spent exploring the familiar object A; TB: time spent exploring the novel object B].

2.13. Mouse Brain MRI. The mice were scanned by MRI after treatment with water or AP39 for 6 weeks as described previously in the literature [31]. The MRI experiment was conducted in Da Ping Hospital, Research Institute of Surgery, Third Military Medical University, China. The mice were anesthetized with $10 \%$ chloral hydrate-saline and then placed 
in the prone position. Their chests were connected to a life signal detector to monitor their physiological status. The heads of the mice were scanned using a 7.0 T ultrahigh field animal MRI scanner (7.0 T ClinScan system, Bruker BioSpin, Ettlingen, Germany). T2-weighted images of the mouse heads were acquired from the sagittal plane, axial direction, and coronal plane according to the following conditions: $\mathrm{TR}=$ $3200 \mathrm{~ms}$, TE $=45 \mathrm{~ms}$, field of view $(\mathrm{FOV})=22 \times 22 \mathrm{~mm}$, slice thickness $=0.5 \mathrm{~mm}$, a scan matrix $=384 \times 384$, and repetitions $(\mathrm{NEX})=5$.

2.14. ELISA for $A \beta_{40}$ and $A \beta_{42}$. A commercially available ELISA kit for $\mathrm{A} \beta_{40}$ and $\mathrm{A} \beta_{42}$ was purchased from Invitrogen. The plasma from samples was collected by centrifugation $\left(1,000 \mathrm{~g}\right.$ at $4^{\circ} \mathrm{C}$ for $\left.10 \mathrm{~min}\right)$, and $100 \mu \mathrm{L}$ of plasma was used for $\mathrm{A} \beta_{40}$ and $\mathrm{A} \beta_{42}$ measurement. The secreted levels of $\mathrm{A} \beta_{40}$ and $\mathrm{A} \beta_{42}$ in blood were quantitatively measured according to the manufacturer's instructions.

2.15. Immunohistochemistry. After the behavioral tests, the mice were deeply anaesthetized with chloral hydrate (400 $\mathrm{mg} / \mathrm{kg}$ body weight) and sacrificed for the preparation of brain slices [32]. The brains were removed from the skull, postfixed overnight in $4 \%$ paraformaldehyde at $4^{\circ} \mathrm{C}$, and transferred to $30 \%$ sucrose solution for dehydration. Subsequently, the brains were frozen and sliced into $30-\mathrm{mm}$ thick sections using a Leica CM3050 S cryostat. After multiple washes in PBS, the slices were incubated with a 6 E10 primary antibody ( $1: 1,000$ diluted) in $10 \%$ goat serum overnight at $4^{\circ} \mathrm{C}$. The tissue sections were washed 3 times for $10 \mathrm{~min}$ in PBS and then incubated with a TRITC-conjugated goat anti-mouse IgG antibody at room temperature for $1 \mathrm{~h}$ followed by PBS washing. The slides were subsequently stained with diaminobenzidine and counterstained with hematoxylin. The images were acquired using a 10x objective on a Carl Zeiss LSM780 confocal microscope (Olympus BX60, Tokyo, Japan). The A $\beta$ plaque areas were quantified using Image-Pro Plus 6.0 software.

2.16. Statistical Analysis. All statistical analyses were performed using SPSS 22.0 software. All data were presented as the means \pm SEM. The data in the Morris water maze were analyzed using two-way ANOVA coupled with a post hoc Fisher's LSD test using GraphPad Prism 6.0 software. The data from other experiments were analyzed by one-way ANOVA coupled with Dunnett's posttest using GraphPad Prism 6.0 software, and $P \leq 0.05$ was considered to be statistically significant.

\section{Results}

3.1. AP39 Increased the Generation of $\mathrm{H}_{2} \mathrm{~S}$ in Neurons and Mitochondria. $\mathrm{H}_{2} \mathrm{~S}$ levels were comparable between WT neurons treated with different concentrations of AP39 for 2 h. AP39 (25-250 nM) induced a concentration-dependent increase in $\mathrm{H}_{2} \mathrm{~S}$ generation and in the fluorescence of the $\mathrm{H}_{2} \mathrm{~S}$-detecting dye AzMC, and the signal was significantly colocalized with the mitochondria (Figures $1(\mathrm{a})$ and 1(b)). Notably, baseline fluorescent signal was detectable in the neurons. In this study, the low basal levels of $\mathrm{H}_{2} \mathrm{~S}$ did not indicate a mitochondrial preference (Figure 1(b)). In conclusion, the data in Figure 1 indicate that AP39 contributes to the synthesis of $\mathrm{H}_{2} \mathrm{~S}$ in neurons, especially in the mitochondria.

3.2. Biphasic Effects of AP39 on Cellular Bioenergetics. Similar to the responses previously noted for authentic $\mathrm{H}_{2} \mathrm{~S}[25,33$, 34], exposure of WT neurons to AP39 induced a significant increase in the basal OCR at $100 \mathrm{nM}$ but induced a decrease in the basal OCR at $250 \mathrm{nM}$ (Figure 2(a)). Additionally, AP39 caused a dose-dependent increase in the FCCP-stimulated OCR at 25 and $100 \mathrm{nM}$ but caused a decrease in the FCCPstimulated OCR at $250 \mathrm{nM}$ (Figure 2(b)). The FCCP-induced increase in the OCR represents the "maximal respiration." Thus, AP39 acts as a supplemental bioenergetic stimulator at low concentrations. The pattern of the effects of AP39 is consistent with the previously established bell-shaped pharmacological properties of $\mathrm{H}_{2} \mathrm{~S}[19,35]$. These results demonstrated that this inhibitory effect is only conspicuous at higher concentrations (Figure 2(b)).

3.3. AP39 Exerted Cytoprotective Effects on APP/PS1 Neurons. We cultured cortical neurons from the brains of embryonic APP/PS1 transgenic mice as an experimental model to study the effects of AP39. We detected the levels and time course of the release of $\mathrm{A} \beta_{42}$ from these neurons into the culture media by ELISA. Figure 3(a) shows that at 3 DIV a small amount of $\mathrm{A} \beta_{42}$ was released into the media of neurons cultured from APP/PS1 mice, but significant differences were observed between neurons cultured from APP/PS1 mice and their WT littermates $(16.1 \pm 6.9$ and $5.9 \pm 2.7 \mathrm{pg} / \mathrm{mL}$, resp.). By $7 \mathrm{DIV}$, the level of $\mathrm{A} \beta_{42}$ produced in the cultures from the APP/PS1 mice was significantly higher than that produced in the cultures from the WT mice $(285.7 \pm 38.6$ versus $6.2 \pm 0.7 \mathrm{pg} / \mathrm{mL}, P<$ $0.01)$, and this level was further increased at 16 DIV $(898.3 \pm$ 27.3 versus $6.8 \pm 0.5 \mathrm{pg} / \mathrm{mL}, P<0.01)$. The total protein from WT and APP/PS1 neurons was extracted separately and analyzed by Western blot. We observed that $\mathrm{A} \beta$ was overexpressed in the APP/PS1 primary neurons compared to the WT neurons (Figures 3(b) and 3(c)).

Exposure of WT neurons to AP39 for $24 \mathrm{~h}$ had no effect on cell viability, but treating the APP/PS1 neurons with AP39 $(25,100 \mathrm{nM})$ for $24 \mathrm{~h}$ resulted in increase in cell viability (Figures 3(d) and 3(e)). To confirm this result, we measured the release of $\mathrm{LDH}$ in the supernatant of the primary neurons. AP39 had no effect on basal LDH release in WT neurons, but there was a significant increase in the amount of $\mathrm{LDH}$ in the APP/PS1 neuron culture medium. This result indicated a loss of cell membrane integrity and an increase in cell necrosis. In contrast, after treatment with AP39, particularly at $100 \mathrm{nM}$, the amount of LDH in the APP/PS1 neuron culture medium was decreased (Figures 3(f) and 3(g)).

3.4. AP39 Attenuated the Loss of Cellular Bioenergetics and Protected Mitochondrial Function in APP/PS1 Neurons. To investigate the effects of AP39 on mitochondrial dysfunction, we measured cellular bioenergetics using the XF24 Extracellular Flux Analyzer. Cellular bioenergetic parameters were significantly decreased in the mitochondria of APP/PS1 


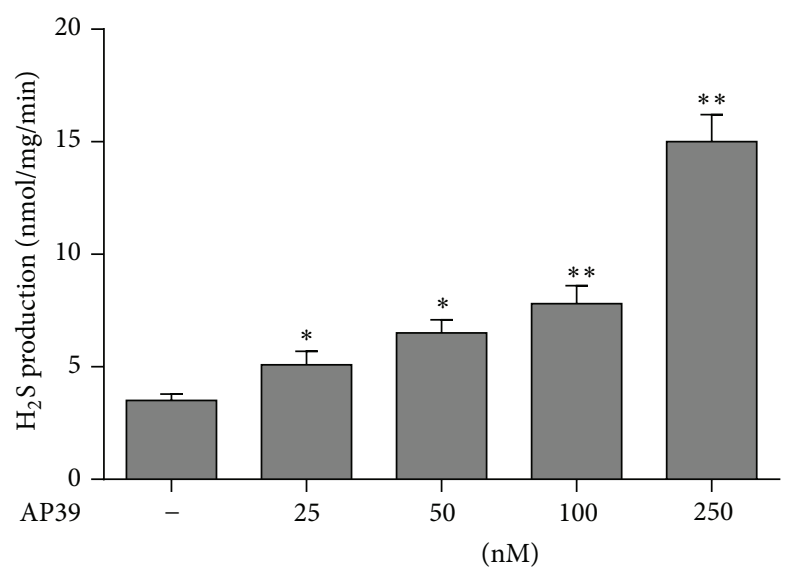

(a)
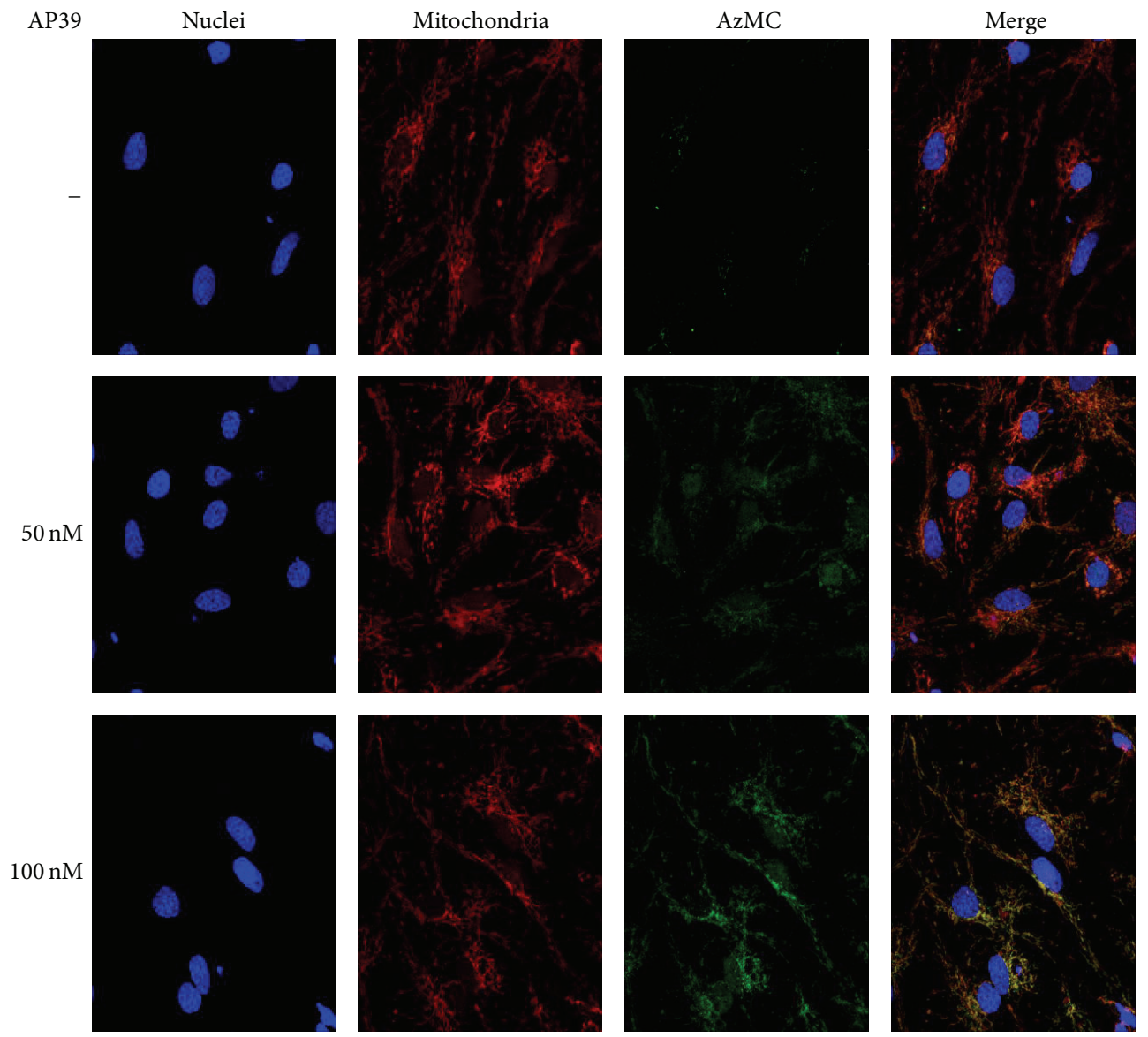

(b)

FIgURE 1: AP39 generates $\mathrm{H}_{2} \mathrm{~S}$ in WT neurons, primarily in the mitochondria. (a) The contribution of AP39 to $\mathrm{H}_{2} \mathrm{~S}$ production in neurons. Neurons from WT mice were treated with various concentrations of AP39 for $2 \mathrm{~h}$, and $\mathrm{H}_{2} \mathrm{~S}$ production was detected by methylene blue assay. (b) Neurons were treated with different concentrations of AP39 for $2 \mathrm{~h}$, and intracellular $\mathrm{H}_{2} \mathrm{~S}$ was detected using the fluorescent probe AzMC. DAPI was used to stain nuclei, and MitoTracker was used to stain mitochondria. The colocalization of $\mathrm{H}_{2} \mathrm{~S}$ with mitochondria was indicated by the overlapping of red (mitochondria) and green $\left(\mathrm{H}_{2} \mathrm{~S}\right)$ fluorescence in the merged image. Note the concentration-dependent increase in the $\mathrm{H}_{2} \mathrm{~S}$ signal in response to AP39 treatment. ${ }^{*} \mathrm{P}<0.05,{ }^{* *} \mathrm{P}<0.01$ compared with control treatment (no AP39). 


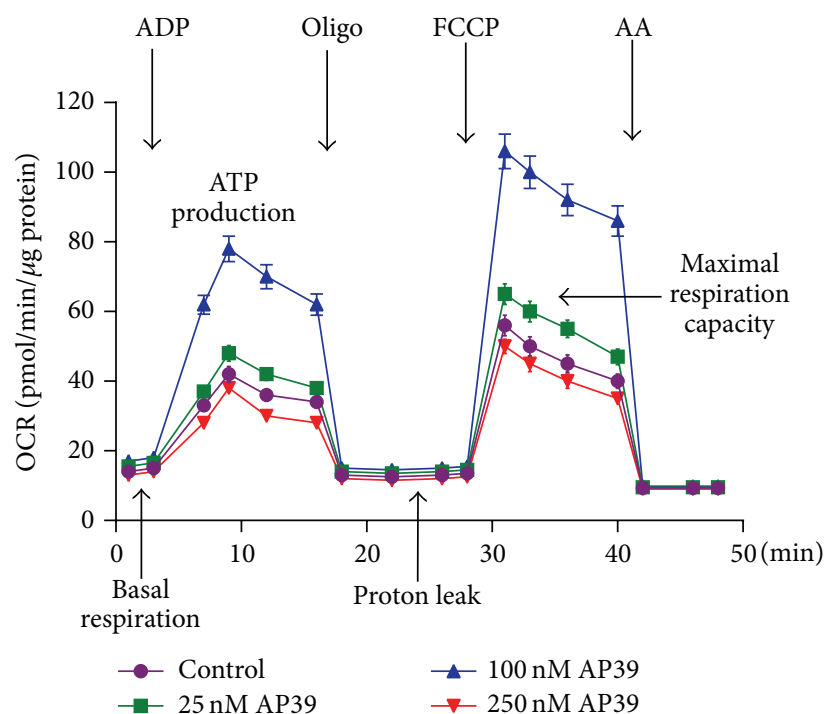

(a)

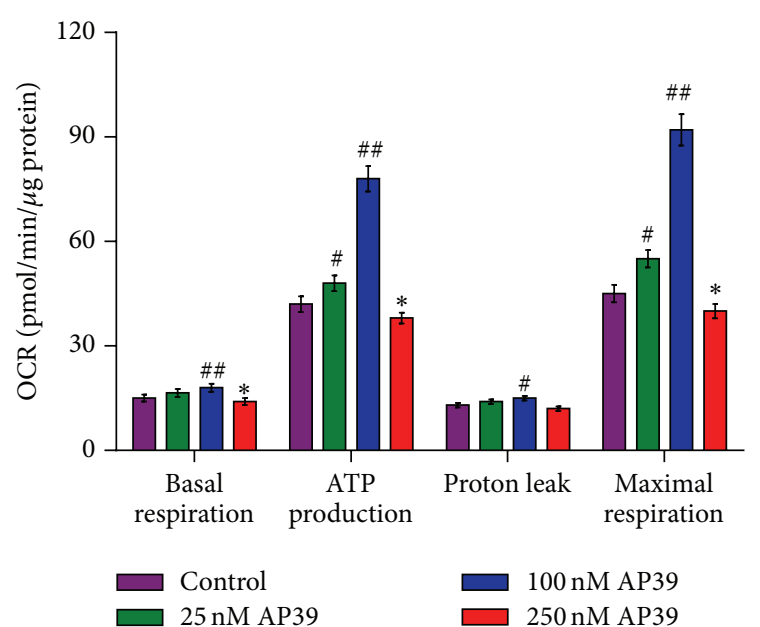

(b)

FIgURE 2: Biphasic effects of AP39 on the cellular bioenergetics of the WT neurons. Neurons from WT mice were incubated in AP39 (25$250 \mathrm{nM}$ ) for $2 \mathrm{~h}$, and bioenergetic parameters were measured using an Extracellular Flux Analyzer. (a) Representative tracings. (b) The calculated bioenergetic parameters. \# and \#\# indicate a significant enhancement in the bioenergetic parameter, compared to the control group (no AP39) $(P<0.05$ and $P<0.01$, resp.); * indicates a significant reduction in the bioenergetic parameter, compared to the control group $(P<0.05)$.

neurons compared with those of WT neurons. Importantly, AP39 (100 nM) significantly increased the basal respiratory rate and the OCR-linked maximal respiratory capacity of the APP/PS1 neurons (Figure 4). These data indicated that AP39 may attenuate the loss of cellular bioenergetics in APP/PS1 neurons.

ATP production, mitochondrial DNA (mtDNA) integrity, and ROS production were measured to evaluate mitochondrial function. AP39 significantly increased the ATP production in WT and APP/PS1 neurons (Figure 5(a)). Next, mtDNA and nuclear genomic DNA integrity was assessed via PCR of long DNA fragments. We found that mtDNA but not nuclear DNA integrity was clearly reduced in APP/PS1 neurons, compared to WT neurons. However, AP39 significantly protected against mtDNA damage in APP/PS1 neurons by partially restoring mtDNA integrity (Figure 5(b)).

Intracellular ROS levels are a basic indicator of oxidative stress. A fluorescence assay using a DCFH-DA probe was performed to quantify the generation of ROS. AP39 (100 nM) effectively decreased ROS levels in APP/PS1 neurons (Figures $5(c)$ and $5(d)$ ). In conclusion, these results suggested that AP39 protects against mitochondrial dysfunction in APP/PS1 neurons.

3.5. AP39 Shifted the Mitochondrial Dynamics toward Fission in APP/PS1 Neurons. The changes in the levels of proteins involved in mitochondrial dynamics (Drp1, Fis1, Mfn1, Mfn2, and OPA1) were determined via Western blot analysis (Figure 6). The levels of these mitochondrial dynamicsrelated proteins were shifted toward fission in APP/PS1 neurons. The levels of the mitochondrial fusion proteins Mfnl and OPA1 were significantly reduced, and the level of the mitochondrial fission protein Fisl was markedly increased in APP/PS1 neurons compared with WT neurons. The protein levels of Mfn2 and Drp1 were not significantly different between APP/PS1 and WT neurons. OPA1, Mfn1, and Mfn2 catalyze mitochondrial fusion. AP39 increased the levels of OPA1 and Mfn1 but not Mfn2. Moreover, AP39 decreased the levels of Fis1 but not Drp1. These findings suggested that AP39 may shift mitochondrial dynamics in APP/PS1 neurons from fission towards fusion.

3.6. AP39 Increased the Generation of $\mathrm{H}_{2} \mathrm{~S}$ in WT and APP/PS1 Mice. AP39 (25-250 nM) induced a dosedependent increase in $\mathrm{H}_{2} \mathrm{~S}$ generation in the cortex and hippocampus of WT and APP/PS1 mice (Figures 7(a) and 7(b)). We also observed that $\mathrm{H}_{2} \mathrm{~S}$ levels in the cortex were lower than those of the hippocampus. However, the level of $\mathrm{H}_{2} \mathrm{~S}$ was significantly decreased in APP/PS1 mice compared to WT mice. In conclusion, the data indicate that AP39 contributes to the synthesis of $\mathrm{H}_{2} \mathrm{~S}$ in WT and APP/PS1 mice.

3.7. AP39 Reversed the Memory Deficits of APP/PS1 Transgenic Mice. The APP/PS1 transgenic mice developed a pronounced spatial learning and memory deficit and produced $\mathrm{A} \beta$ plaques by 12 months of age [22]. To test the ability of AP39 to ameliorate the spatial learning deficits of the AD model mice, we treated 12-month-old AD model mice and WT controls with $100 \mathrm{nM} / \mathrm{kgAP} 39$. Then, behavioral testing was initiated 6 weeks after the initiation of AP39 therapy using the Morris water maze and the NORT. 


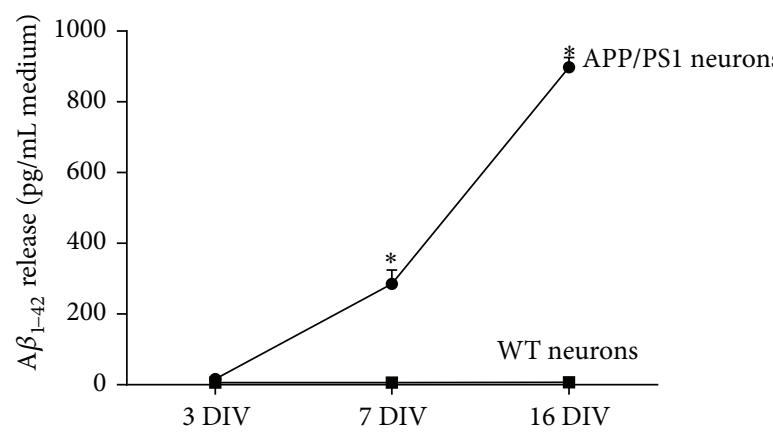

(a)

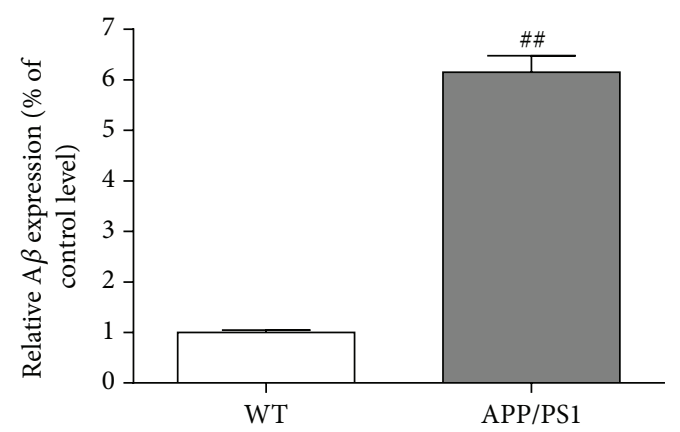

(c)

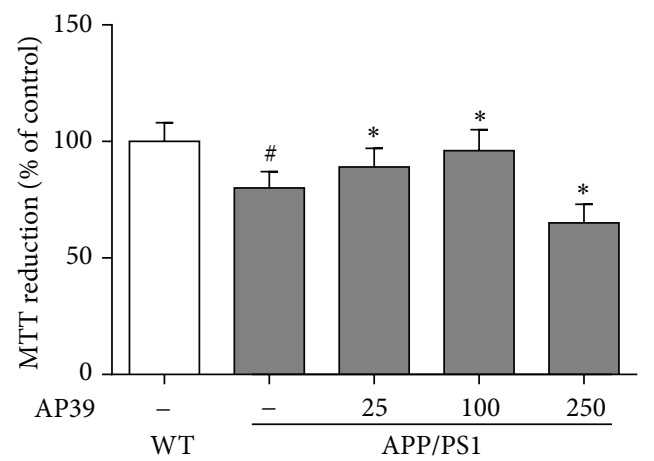

(e)

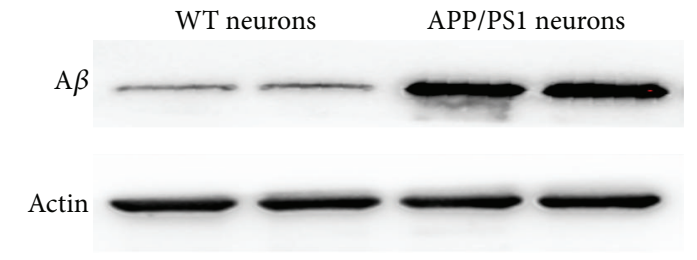

(b)

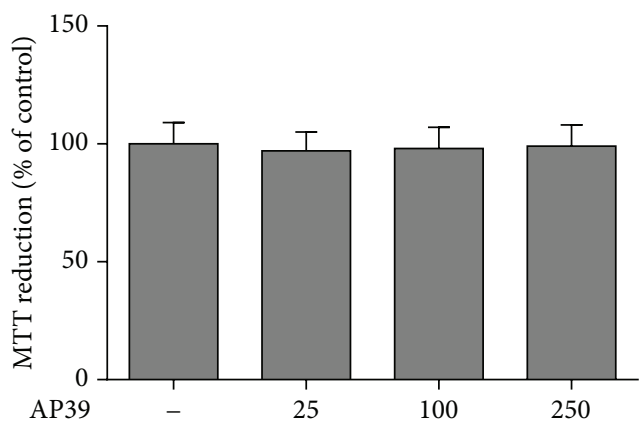

(d)

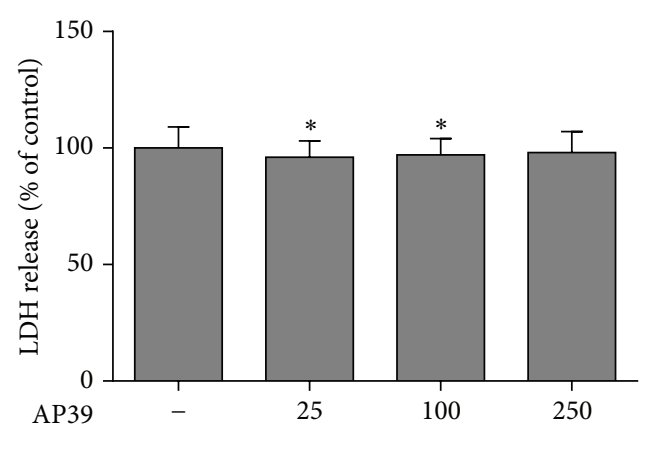

(f)

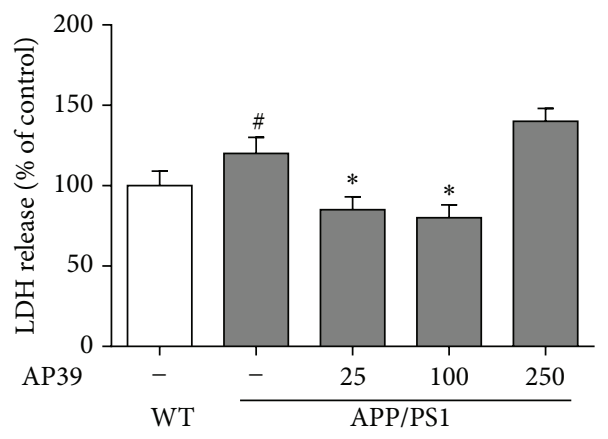

(g)

Figure 3: Cytoprotective effects of AP39 in APP/PS1 neurons. (a) A time course shows that increasing levels of A $\beta_{42}$ are released into the culture media of neurons from transgenic mice but not their WT littermates. (b) A $\beta$ was overexpressed in neurons from APP/PS1 mice compared to $\mathrm{A} \beta$ expression in neurons from their WT littermates. (c) Representative of $A \beta$ blots is shown with quantification. (d) The effects of AP39 (25-250 nM) treatment for $24 \mathrm{~h}$ on cell viability in WT neurons. AP39 alone did not affect MTT conversion. (e) The effects of AP39 (25-250 nM) on MTT conversion in APP/PS1 neurons. There was a decrease in MTT conversion in the APP/PS1 neurons compared to the WT neurons; these effects were attenuated by AP39. (f) After treatment of WT neurons with AP39 for $24 \mathrm{~h}$, AP39 alone did not affect LDH release in the cellular medium. (g) The effects of AP39 on LDH release from APP/PS1 neurons. ${ }^{*} P<0.05$, versus the APP/PS1 group; ${ }^{\#} P<0.05$, the APP/PS1 group versus the WT group. 


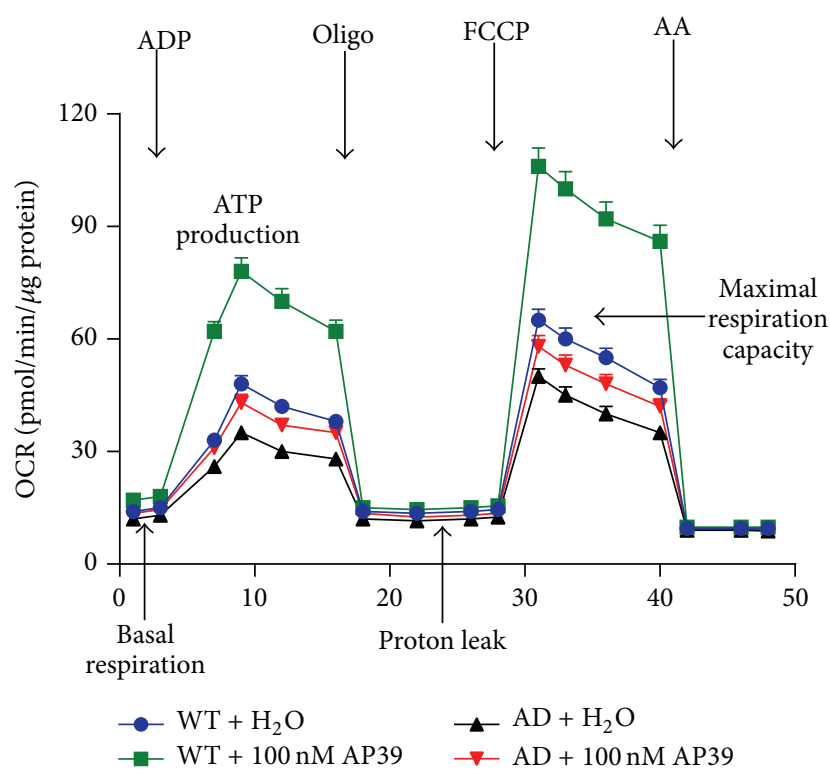

(a)

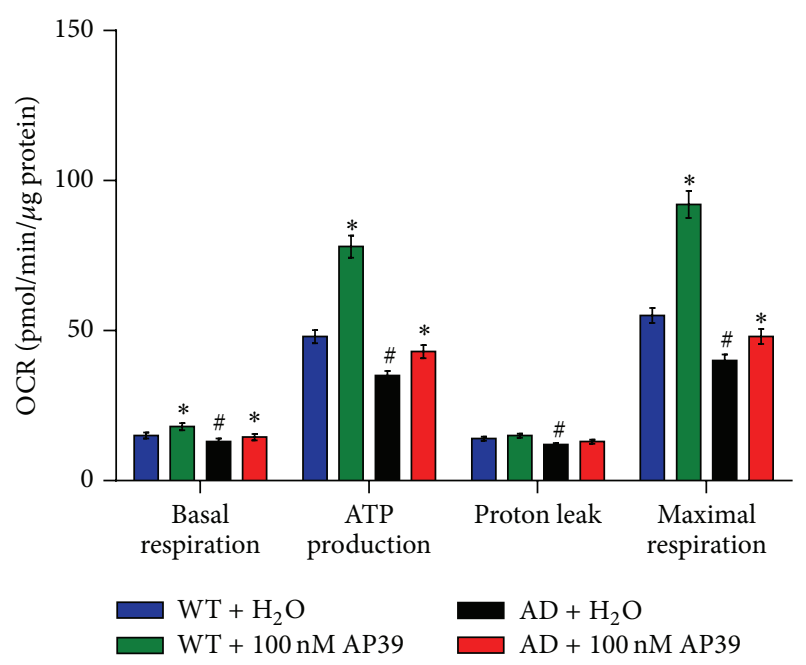

(b)

FIGURE 4: Protective effects of AP39 on the cellular bioenergetics of APP/PS1 neurons. APP/PS1 neurons were incubated in AP39 (100 nM) for $24 \mathrm{~h}$, and bioenergetic parameters were measured using the Extracellular Flux Analyzer. (a) Representative tracings are shown. (b) The calculated bioenergetic parameters are shown. * indicates a significant enhancement of the bioenergetic parameter compared to the control $\left(\mathrm{H}_{2} \mathrm{O}\right)(P<0.05)$; \# indicates a significant reduction in the bioenergetic parameter compared to the control $\left(\mathrm{WT}+\mathrm{H}_{2} \mathrm{O}\right)(P<0.05)$.

In the training trials, treatment with AP39 for 6 weeks eliminated the preexisting deficits of the transgenic mice, as demonstrated by a reduced latency to locate the hidden platform compared to the latency of the WT control with AP39 (Figure 8(a)). The WT mice with or without AP39 treatment preferred the target quadrant in the probe trial. In contrast, the $\mathrm{AD}$ model mice treated with $\mathrm{H}_{2} \mathrm{O}$ spent much less time in the target quadrant, near the chance level of $15 \mathrm{~s}$. The AD model mice treated with AP39 showed the same strong preference for the target quadrant as the WT mice. Thus, after 6 weeks, AP39 treatment reversed the spatial learning and memory deficits of the aged AD model mice (Figure $8(\mathrm{~b})$ ). This benefit was concentration-dependent, as $25 \mathrm{nM} / \mathrm{kg}$ AP39 treatment did not improve the water maze performance of the AD model mice (Figure 8(c)). Next, the same mice with $100 \mathrm{nM} / \mathrm{kg} \mathrm{AP39}$ or $\mathrm{H}_{2} \mathrm{O}$ treatment were subjected to the NORT test (Figure $8(\mathrm{~d})$ ). The NORT test does not put stress on the animal and does not require spatial orientation. It has been used to measure deficits in learning and memory in various $\mathrm{AD}$ mouse models $[36,37]$. Importantly, $\mathrm{AD}$ mice treated with water performed poorly and presented an impairment compared to the WT mice, indicated by a significant reduction in the percentage of time exploring the novel object; this behavior was consistent with an impairment in memory function for familiarization on the previous day. In contrast, the AP39-treated AD mice showed significantly improved performance levels compared to the water-treated AD mice level. Thus, treatment of aged APP/PS1 mice with $100 \mathrm{nM} / \mathrm{kg}$ AP39 for 6 weeks reversed the age-dependent memory impairment. All of these results indicated that appropriate doses of AP39 improved the learning and working memory ability of $\mathrm{AD}$ model mice.
3.8. AP39 Inhibited the Brain Atrophy of APP/PS1 Transgenic Mice. In addition to behavioral assessments, mice were randomly selected for intravital scanning to noninvasively study brain structure using MRI data. We studied the coronal and axial sections of the mouse brains (Figures 9(a)-9(f)). As expected, there were no apparent structural abnormalities in the WT mouse brains. For example, the sizes of the ventricle were symmetric between the two brain hemispheres, and the edges of the ventricle were clear and sharp (Figures 9(a) and 9(b)). However, we observed visible atrophy in the brains of the 12-month-old AD model mice treated with water (Figures $9(\mathrm{c})$ and $9(\mathrm{~d}))$. Their ventricles were asymmetric, with a much larger size on the right than the left side, and had unclear edges. The MRI imaging data revealed that AP39 might alleviate brain atrophy and ventricle asymmetry in $\mathrm{AD}$ model mice (Figures 9(e) and 9(f)).

The apparent diffusion coefficient (ADC) value in parietal cortex and hippocampus of each group of mice was compared with diffusion weighted imaging (DWI) sequences. Figure 9(g) showed the ADC value in parietal cortex and hippocampus of APP/PS1 mice significantly declined compared to those in WT mice, whereas AP39 significantly increased the ADC values in parietal cortex and hippocampus of APP/PS1 mice $(P<0.05)$.

3.9. AP39 Reduced the Levels of $A \beta$ and $A \beta$ Deposition in APP/PS1 Transgenic Mice. After different treatments for 6 weeks, $\mathrm{A} \beta$ levels and plaque development were examined in vivo. The $\mathrm{A} \beta_{40}$ and $\mathrm{A} \beta_{42}$ levels in the 12 -month-old $\mathrm{AD}$ transgenic model mouse brains were 925 and $532 \mathrm{pg} / \mathrm{mL}$, respectively. Importantly, treatment with $100 \mathrm{nM} / \mathrm{kg}$ AP39 decreased the $\mathrm{A} \beta_{40}$ and $\mathrm{A} \beta_{42}$ levels in $\mathrm{AD}$ mice compared 

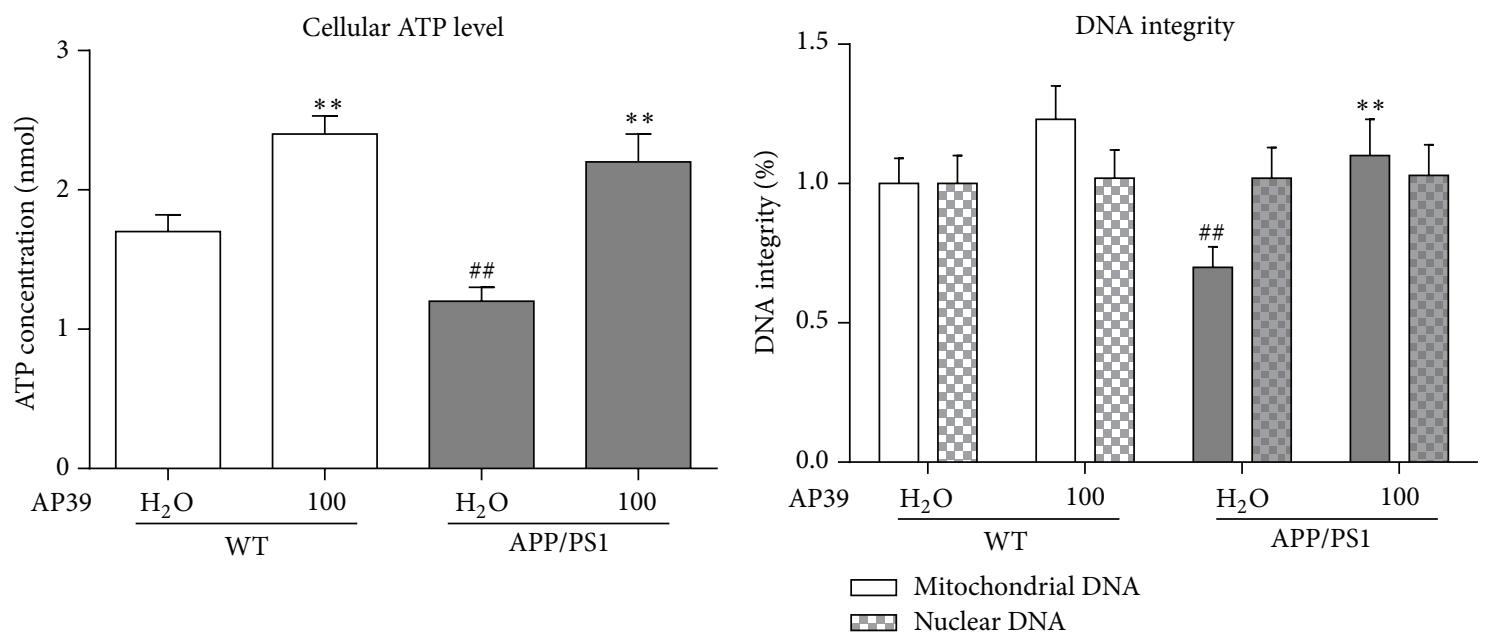

(a)

(b)
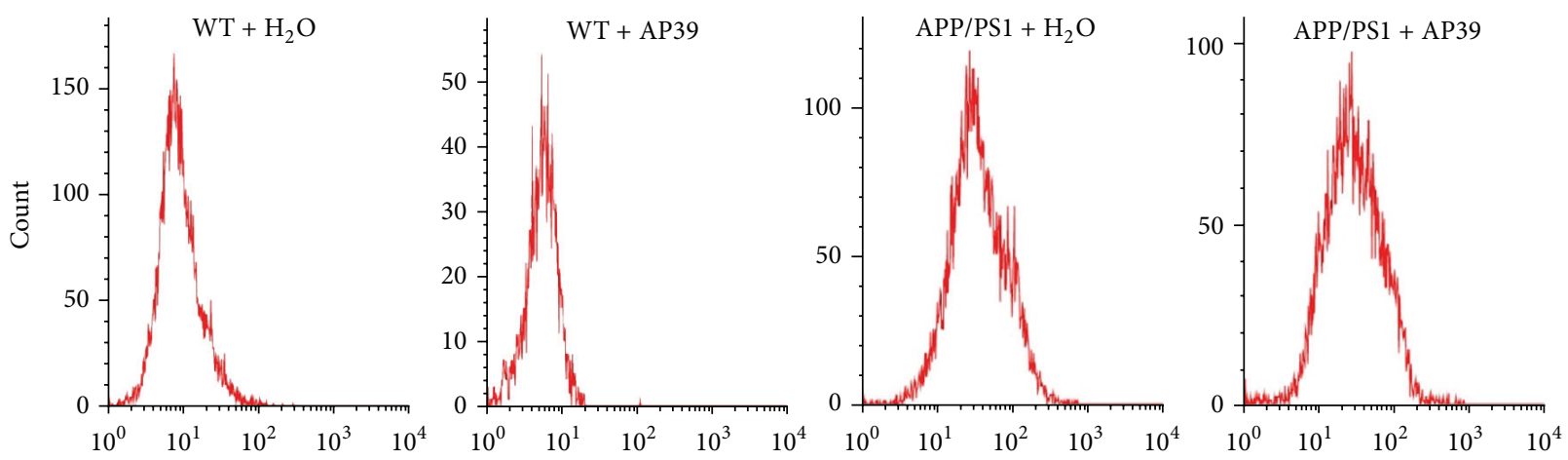

(c)

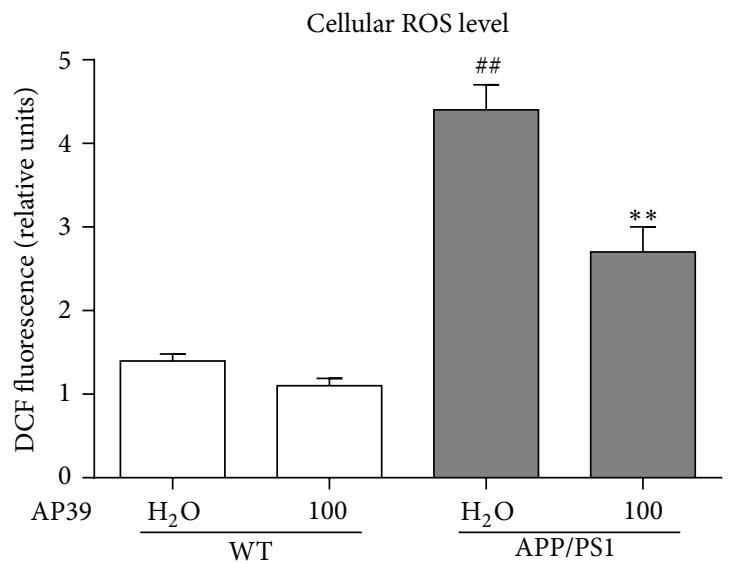

(d)
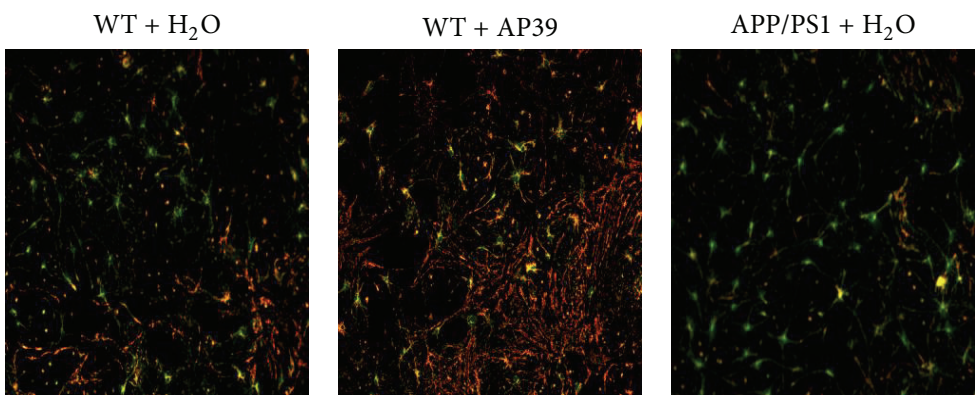

APP/PS1 + AP39

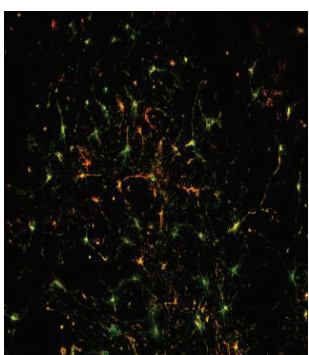

(e)

Figure 5: Continued. 


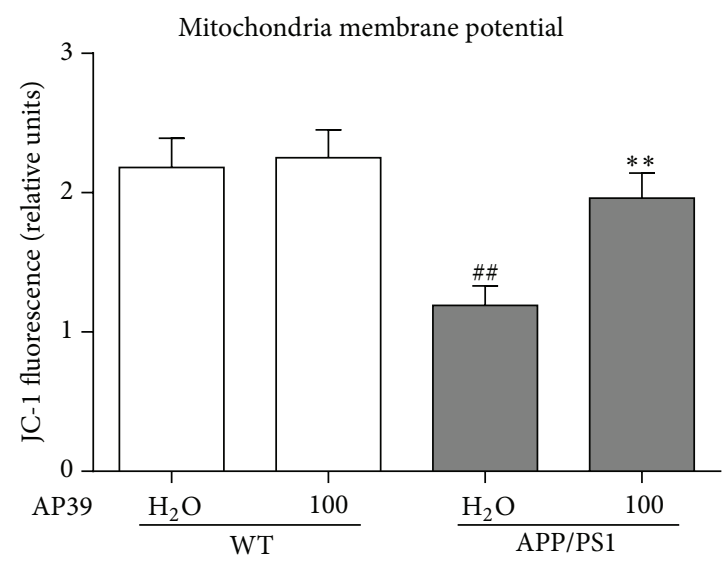

(f)

FIGURE 5: AP39 protected mitochondrial function in APP/PS1 neurons. (a) AP39 increased the cellular ATP levels. (b) AP39 protected mtDNA integrity. (c) ROS levels were detected by flow cytometry. (d) AP39 reduced ROS levels. ${ }^{\# \#} P<0.01$, compared with the WT group; ${ }^{* *} P<0.01$, compared with the control group $\left(\mathrm{H}_{2} \mathrm{O}\right)$.

to water treatment (Figures 10(a) and 10(b)). As expected, amyloid plaques were not observed in WT mice. However, intracellular amyloid in the hippocampal and cortical tissues of the $\mathrm{AD}$ model mice treated with water was remarkably increased compared with the WT control mice. This observation is consistent with those from a previous study [31]. Importantly, treatment with AP39 significantly reduced both the number and the size of intracellular amyloid plaques in the cortical and hippocampal tissues compared to treatment with water in the AD mice (Figure 10(c)). The amyloid plaque burden in the brains of AD model mice treated with AP39 was decreased compared with the brains of AD mice treated with water (Figure 10(c)). These results demonstrated the ability of AP39 to inhibit A $\beta$ plaque deposition in the brains of AD mice.

\section{Discussion}

Our findings demonstrate that AP39, a newly synthesized mitochondrially targeted $\mathrm{H}_{2} \mathrm{~S}$ donor, maintains cellular bioenergetics and exerts mitochondrial protective effects in AD neurons and mice. First, AP39 exerted concentrationdependent modulatory effects on cell viability and cellular bioenergetic function. At 25 or $100 \mathrm{nM}$, AP39 enhanced cell viability and bioenergetics, but the highest AP39 concentration $(250 \mathrm{nM})$ reduced these parameters in APP/PS1 neurons. In addition, treatment with an appropriately selected concentration of AP39 (100 nM) increased ATP levels, protected mtDNA integrity, decreased intracellular ROS levels, and regulated mitochondrial dynamics. Moreover, AP39 significantly inhibited brain atrophy and ameliorated the memory deficits and $\mathrm{A} \beta$ deposition in APP/PS1 mice.

$\mathrm{H}_{2} \mathrm{~S}$, which has recently been determined to be the third most abundant gasotransmitter, plays a variety of physiological and pathological roles in the central nervous system and other systems [38, 39]. An increasing amount of evidence suggests that $\mathrm{H}_{2} \mathrm{~S}$ is a potential therapeutic drug for $\mathrm{AD}$. Recently, it was reported that $\mathrm{H}_{2} \mathrm{~S}$-modulating agents such as
S-ally-l-cysteine (SAC) and Tabiano spa waters (enriched in $\mathrm{H}_{2} \mathrm{~S}$ ) protected against impairments in learning and memory in $\mathrm{AD}$ transgenic mice by modulating inflammation and apoptosis [40-42]. In addition, our group reported that NaHS can promote the nonamyloidogenic processing of APP and improve spatial learning and memory acquisition in APP/PS1 mice [43]. However, due to technical limitations for $\mathrm{H}_{2} \mathrm{~S}$ detection, at present its biological roles and metabolites in vivo have remained elusive, resulting in considerable controversy [44]. Moreover, the use of sulfide salts such as NaHS is limited, although the solutions to these problems have recently become apparent [36]. Importantly, recent studies indicated that AP39 acts as an endogenous $\mathrm{H}_{2} \mathrm{~S}$ donor and exerts antioxidative and cytoprotective effects on bEnd.3 cells [19]. AP39 decreased blood pressure, heart rate, and pulse wave velocity in rats [37]. Based on these limitations and progress, we synthesized AP39 to evaluate its protective effects on mitochondrial function in APP/PS1 mice.

We observed that AP39 increased $\mathrm{H}_{2} \mathrm{~S}$ levels in neurons and mitochondria. Given that AP39 has the TPP+ group, which has been used to selectively target various molecules [45-47], this resulted in AP39 successfully and selectively delivering $\mathrm{H}_{2} \mathrm{~S}$ to mitochondria. This result is consistent with previous literature [19].

Previous research demonstrated that $\mathrm{H}_{2} \mathrm{~S}$ can act as an electron donor and as a potential inorganic source of energy in mammalian cells, resulting in an increase in cellular oxygen utilization and ATP production $[48,49]$. Subsequently, studies reported opposing (stimulatory at lower concentrations; inhibitory at higher concentrations) effects of $\mathrm{H}_{2} \mathrm{~S}$ on cellular bioenergetics in HT-29 Glc $(-/+)$ cells and some immune cells $[50,51]$. However, owing to the various measurement methods used in experiment, the exact concentrations of $\mathrm{H}_{2} \mathrm{~S}$ reported to induce stimulation versus inhibition were different. Recently, Módis et al. reported that 3-MSTderived $\mathrm{H}_{2} \mathrm{~S}$ functions as an endogenous bioenergetic factor that donates electrons to SQR: the subsequent mitochondrial electron transport is coupled to aerobic ATP generation. In 


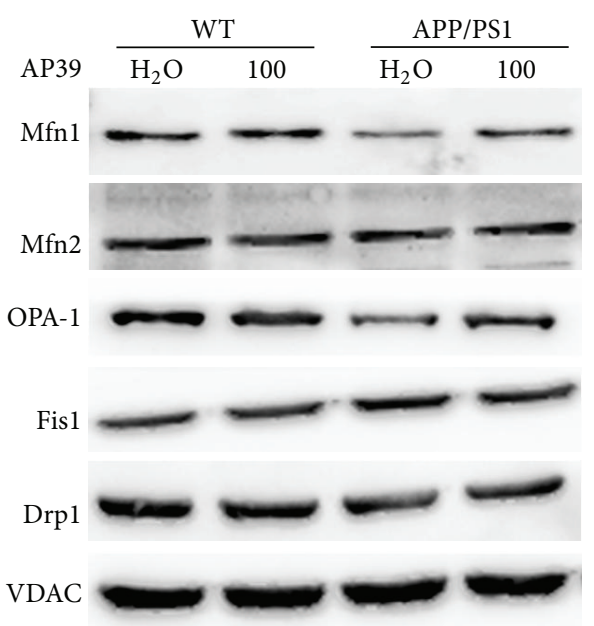

(a)

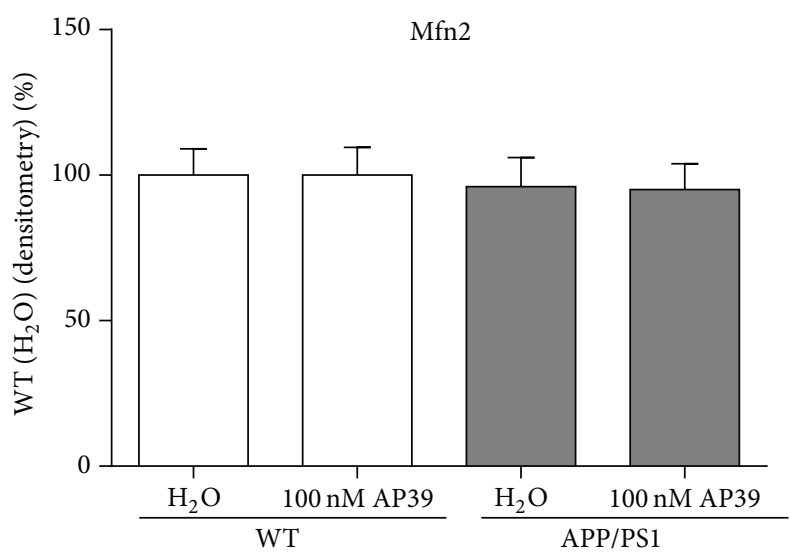

(c)

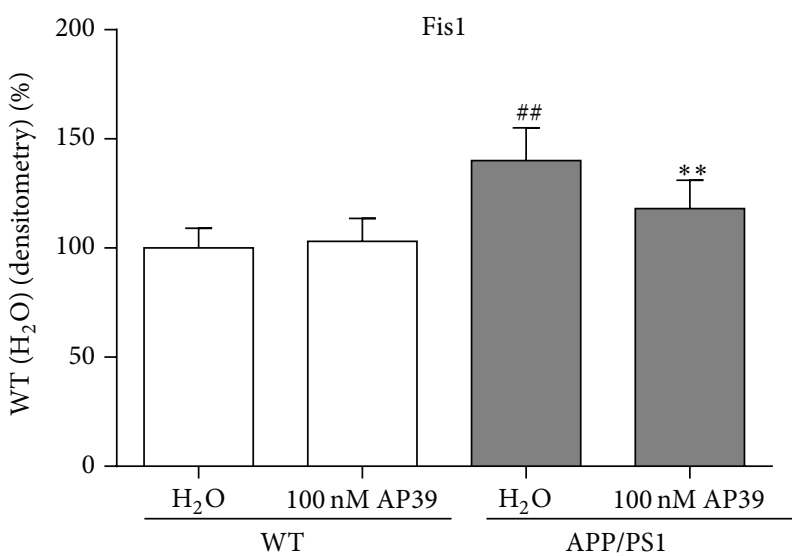

(e)

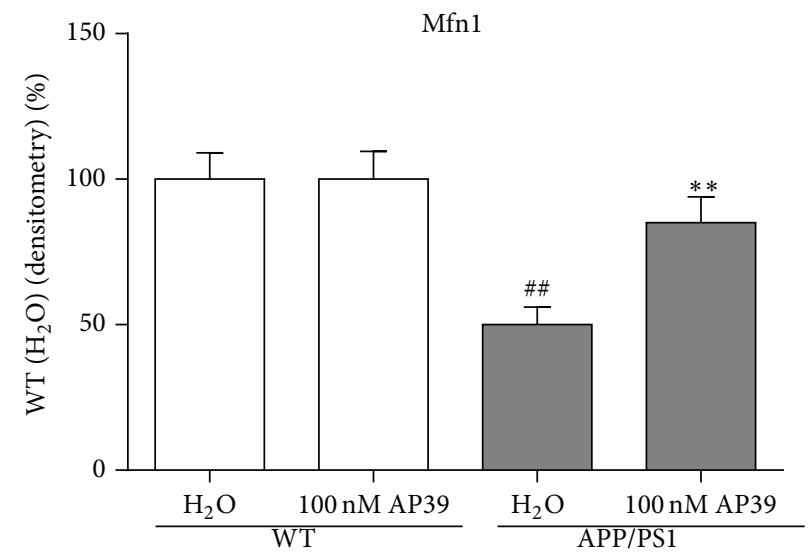

(b)

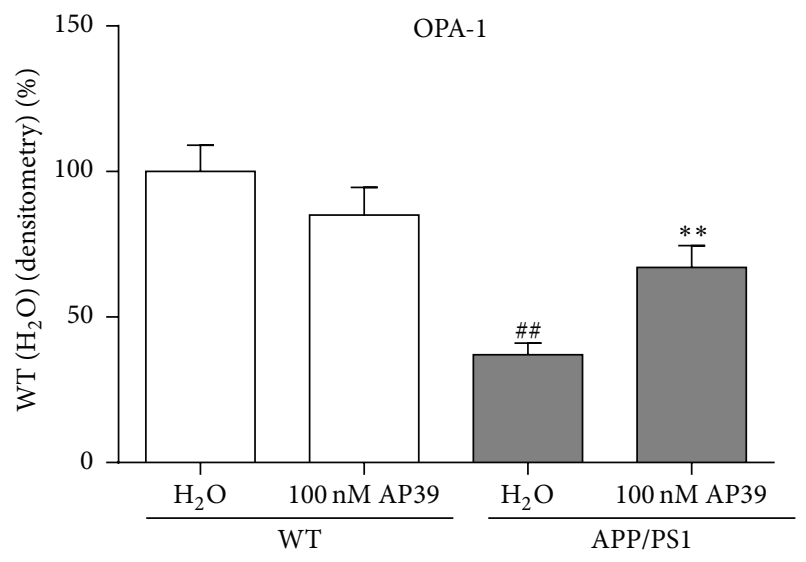

(d)

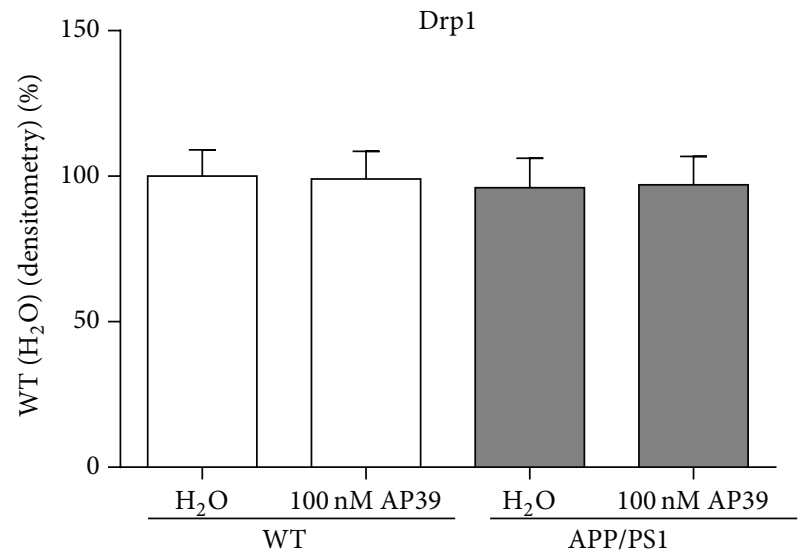

(f)

FiguRE 6: AP39 reduced the expression of proteins involved in mitochondrial fusion but increased the expression of a mitochondrial fission protein. (a) Protein samples were probed for Drp1, Fis1, Mfn1, Mfn2, OPA-1, and VDAC expression. (b-f) Representative blots are shown with quantification. ${ }^{\# \#} P<0.01 \mathrm{AD}$ mice receiving water compared to WT mice receiving water; ${ }^{* *} P<0.01$ mice receiving AP39 compared with mice receiving water. 


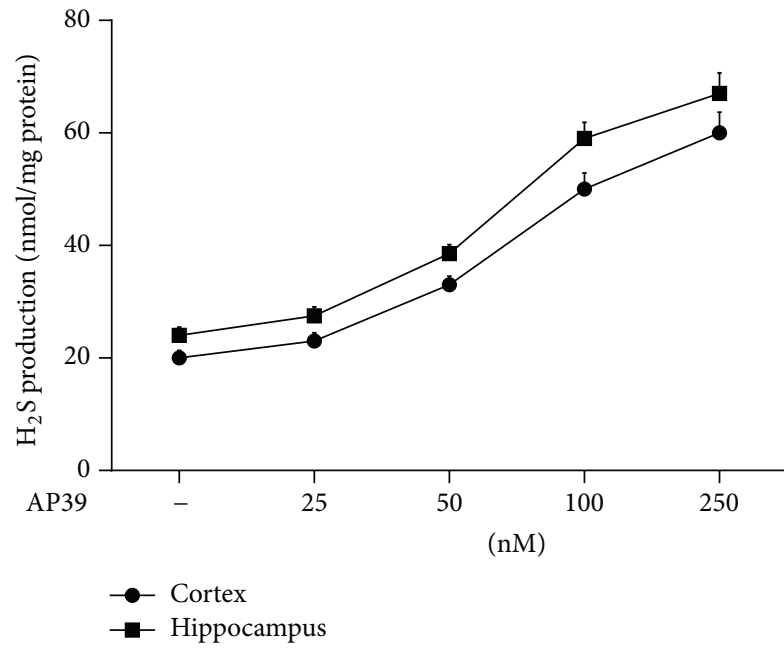

(a)

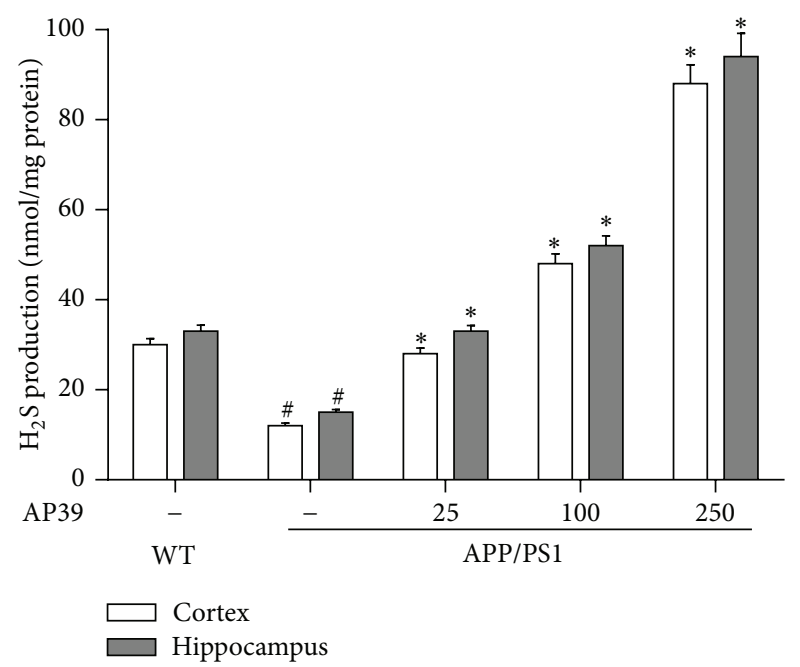

(b)

Figure 7: AP39 generates $\mathrm{H}_{2} \mathrm{~S}$ in WT mice and AP39 increased $\mathrm{H}_{2} \mathrm{~S}$ levels in APP/PS1 mice. (a) The contribution of AP39 to $\mathrm{H}_{2} \mathrm{~S}$ production in the cortex and hippocampus of WT mice. (b) AP39 increased $\mathrm{H}_{2} \mathrm{~S}$ levels in APP/PS1 mice. ${ }^{\#} \mathrm{P}<0.01$, compared with the WT group; ${ }^{* *} P<0.01$, compared with the control group $\left(\mathrm{H}_{2} \mathrm{O}\right)$.

Hepalclc7, low concentrations of $\mathrm{H}_{2} \mathrm{~S}(0.1-1 \mu \mathrm{M})$ elicited a significant increase in mitochondrial electron transport and cellular bioenergetics and higher concentrations of $\mathrm{H}_{2} \mathrm{~S}$ (3$30 \mu \mathrm{M}$ ) were inhibitory [18]. In our experiments, AP39 (25$100 \mathrm{nM}$ ) induced the stimulation of cellular bioenergetics and AP39 (250 nM) induced marked inhibition in WT neurons. Moreover, APP/PS1 neurons exhibited higher "baseline" rates of oxygen consumption, electron transport, and cellular bioenergetic status than WT neurons. However, it is noted that AP39 $(100 \mathrm{nM})$ increased the basal respiratory rate and exerted a protective effect on the cellular bioenergetics of the APP/PS1 neurons. These results are consistent with a previous study showing a stimulatory role for $\mathrm{H}_{2} \mathrm{~S}$ on bioenergetics but are opposed to the inhibitory effects of $\mathrm{H}_{2} \mathrm{~S}$ on mitochondrial electron transport at complex IV [52-54], which occurs at supraphysiological concentrations. Interestingly, the concentrations of AP39 (nM) that resulted in either stimulation or inhibition were lower than those previously reported using $\mathrm{H}_{2} \mathrm{~S}$. We considered that AP39 accumulated in mitochondria, in which the AP39 concentration is likely substantially higher than the "nominal" concentration that was applied to the culture medium, resulting in this discrepancy. Overall, these data indicated that the stimulatory and inhibitory effects of $\mathrm{H}_{2} \mathrm{~S}$ occur in a narrow concentration range (in a specific concentration range to exert positive bioenergetic effects; exceeding this range produces inhibitory effects). However, the exact molecular mechanism underlying the protective effect of AP39 remains to be investigated in further experiments.

It has been reported that transgenic mouse strains harboring a single (APP) or double (APP and PSEN1) genetic mutation generate amyloid plaques [55]. In our experiments, $\mathrm{A} \beta_{42}$ release was significantly decreased in neurons cultured from APP/PS1 mice compared to neurons from WT mice, and this result may be attributed to these two (APP and
PSEN1) gene mutations. Previous reports have commonly used $\mathrm{A} \beta \mathrm{PP}$ cultured primary neurons to evaluate $\mathrm{A} \beta \mathrm{PP}$ processing and $\mathrm{A} \beta$ secretion $[56,57]$ and have shown that $\mathrm{A} \beta$ accumulates intracellularly in $\mathrm{A} \beta \mathrm{PP}$ cultured neurons [58]. Our data are consistent with the reports of these previous studies.

We first evaluated the effects of AP39 on APP/PS1 neurons. In APP/PS1 neurons, cell viability was decreased and LDH release was improved compared to WT neurons. The results may be attributable to the fact that media from the $\mathrm{A} \beta \mathrm{PP}$ primary neuronal cultures contained toxic components that led to neuritic degeneration [59]. However, AP39 improved the situation in a dose-dependent manner. These findings demonstrate the beneficial effects of AP39.

Recently, mtDNA damage and oxidative stress were found to play important roles in the pathogenesis of $\mathrm{AD}$ [60]. $\mathrm{A} \beta$ can decrease mitochondrial energy production, increase ROS levels within the mitochondria, and injure sensitive mtDNA [61]. In our study, treatment of APP/PS1 neurons with AP39 was shown to increase neuronal ATP production and reduce ROS levels. Interestingly, the APP/PS1 neurons showed significant damage to their mitochondrial DNA, and this damage may be due to $\mathrm{A} \beta$ plaque deposition in these neurons. More importantly, we found that AP39 clearly increased mitochondrial, but not nuclear, DNA integrity. Our results suggest that AP39 may partially contribute to the enhancement of mitochondrial biogenesis, the repair of oxidative damage, and the attenuation of mitochondrial dysfunction in AD. However, we can not exclude the possibility that $\mathrm{H}_{2} \mathrm{~S}$ may also affect the integrity or activity of various mitochondrial DNA repair proteins in APP/PS1 neurons. This potential relationship remains to be explored in further experiments. Recently, accumulating evidence has suggested that there is an imbalance in mitochondrial fission and fusion in $\mathrm{AD}$ progression $[62,63]$. Our study showed 


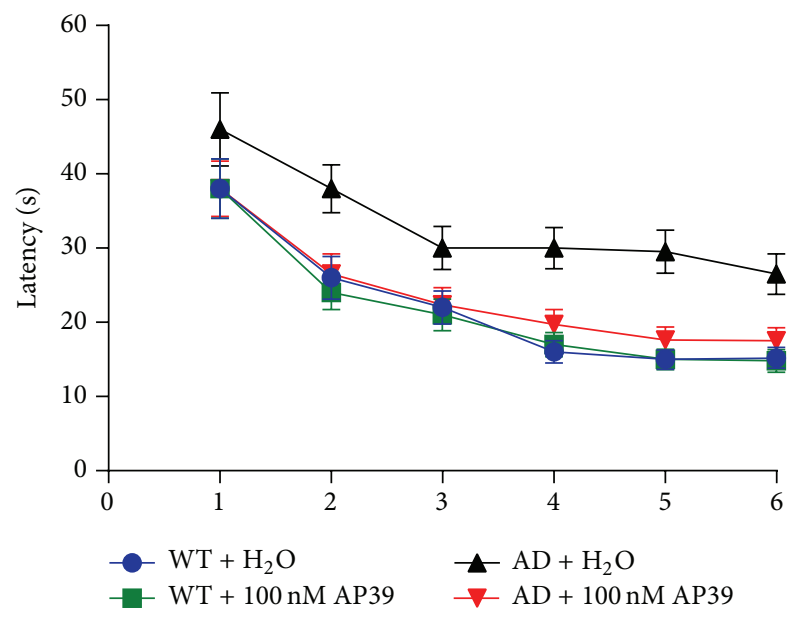

(a)

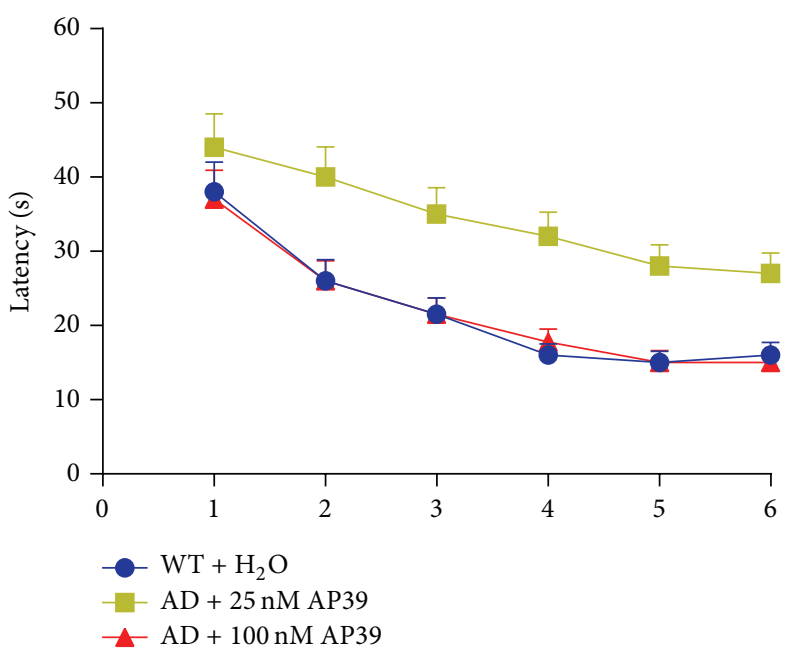

(c)

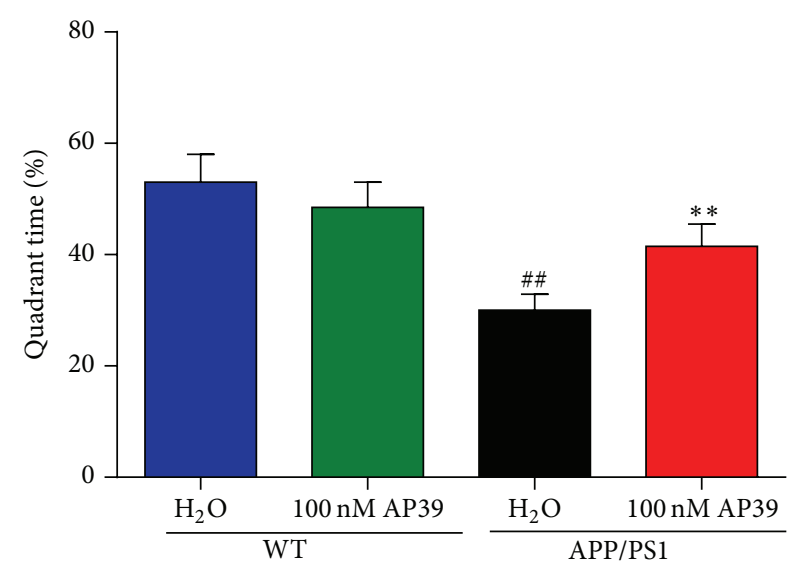

(b)

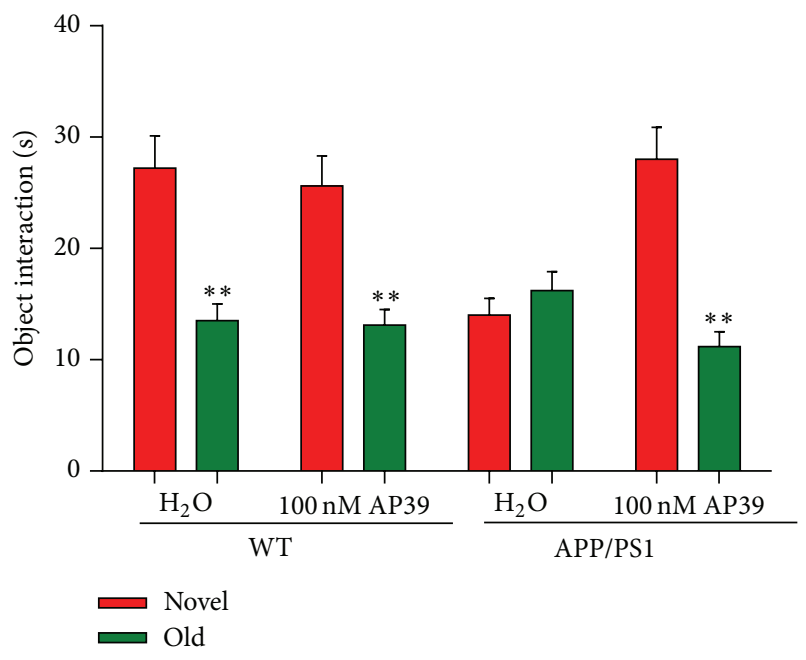

(d)

FIGURE 8: AP39 ameliorated the learning and memory deficits of APP/PS1 mice. WT or AD mice were treated with water or AP39 (100 nM/kg) for 6 weeks, followed by assessment using the Morris water maze and novel object recognition task tests. (a) Spatial learning and memory in $\mathrm{AD}$ mice are scored as the latency to locate a hidden platform. (b) After $24 \mathrm{~h}$, a 60 -s probe trial was performed. (c) Spatial learning was tested as the latency to locate a hidden platform for the $25 \mathrm{nM} / \mathrm{kg}$ AP39-treated mice and scored. (d) Effects of AP39 on the memory performance of 12-month WT or AD mice treated with water or AP39 were tested in the NORT test.

that the levels of the fission proteins Mfnl and OPA1 were significantly decreased but that the levels of the fusion protein Fis1 were markedly increased in APP/PS1 neurons. These results suggested that mitochondrial fission and fusion were altered in APP/PS1 neurons. However, no apparent changes in the levels of the mitochondrial fusion protein Mfn2 or the mitochondrial fission protein Drpl were observed in the APP/PS1 neurons. This result was consistent with the observation of mitochondria with increased fission and decreased fusion based on the related mRNA and protein levels in A $\beta$ PP primary neurons [9]. Importantly, AP39 treatment reversed these changes in APP/PS1 neurons. The molecular basis for the extensive changes in mitochondrial fusion and fission observed in neurons in response to the pathogenesis of mitochondrial-related neurodegenerative diseases has not been described [64]. Interestingly, our data are not consistent with the findings of all previous reports. These inconsistencies may be due to the use of a different experimental model and different environments in vivo and in vitro. Importantly, AP39 treatment reversed these changes in APP/PS1 neurons. Whether the three genes exhibiting altered expression mediate the effects of AP39 on AD is currently under investigation.

To test whether AP39 protects AD model mice against impaired cognitive function, we examined both spatial memory and object recognition memory in APP/PS1 mice. After six weeks of AP39 treatment, the age-dependent memory deficit in the APP/PS1 mice was fully rescued on both memory tests: AP39 ameliorated their spatial learning and memory impairments, as shown by faster movement to the target quadrant of the pool. The reduced swimming time near the periphery of the pool indicated that AP39 can help to relieve anxiety, a common symptom of $\mathrm{AD}$, in mice. In 


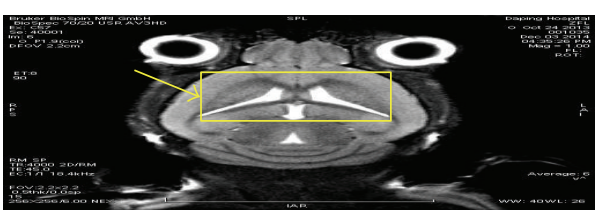

(a)

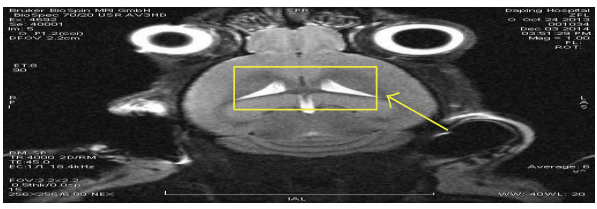

(c)

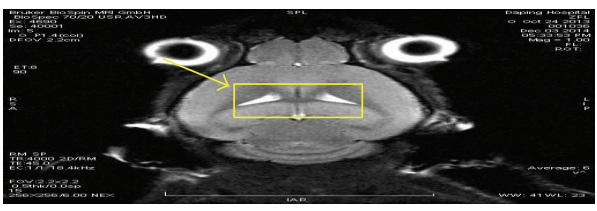

(e)

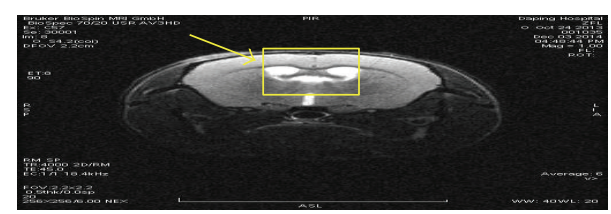

(b)

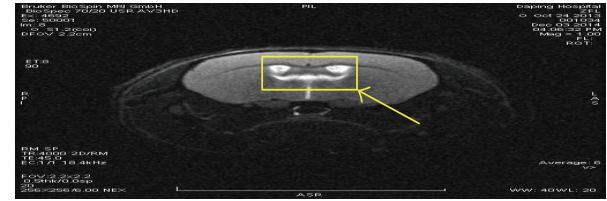

(d)

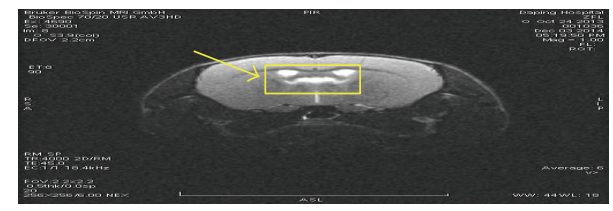

(f)

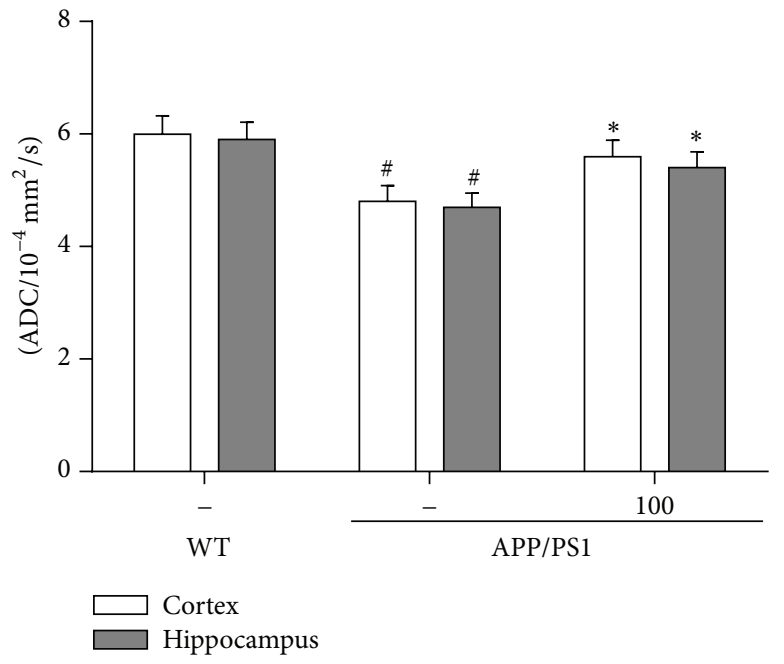

(g)

FIGURE 9: AP39 alleviated the brain atrophy of APP/PS1 mice as observed by brain magnetic resonance imaging (MRI). Brain MRI data were collected at different coronal and axial sections in 12-month-old mice receiving different treatments. Notes: panels (a), (c), and (e) show coronal sections, and panels (b), (d), and (f) show axial sections. The highlighted white regions indicate cerebrospinal fluid (CSF) in the ventricle, and the hippocampus is adjacent to the ventricle. Representative images from brain MRI depict slices of the T2-weighted morphologic images of 12-month-old WT mice treated with water (a)-(b) or AD mice treated with water (c)-(d) or AP39 (e)-(f). (g) ADC value determination of the mouse brains.

the present study, AP39 $(100 \mathrm{nM} / \mathrm{kg})$ was a more effective therapeutic concentration than AP39 $(25 \mathrm{nM} / \mathrm{kg})$. The dosedependence of the observed memory improvement implies that an appropriate dose of AP39 is required for its beneficial effects on learning and memory. It remains possible that higher doses of AP39 are deleterious to memory function.

Due to its advantages, such as noninvasiveness and the ability to perform repeated in vivo measurements, MRI has been widely used in AD research [65] and in the auxiliary clinical diagnosis of $\mathrm{AD}$ [66]. It was used to directly visualize the inner structure of the intravital cerebrum and to measure the in vivo changes in brain volume [67], amyloid burden
[68], and white matter. The hippocampus is a brain area critical for learning and memory and is especially vulnerable to damage in the early stages of AD cases [69]. In our study, the changes in the ventricle, including the deepening and widening of the sulci and the gyri, were clearly observed by MRI. In the water-treated $\mathrm{AD}$ mice, we observed asymmetrical ventricles, which indicated the atrophy of regions surrounding the ventricle. However, in the AP39-treated AD mice, we observed that the ventricles were symmetrical and exhibited clear edges. Because the hippocampus is adjacent to the ventricle, we hypothesized that AP39 may partially prevent hippocampal atrophy. However, we must further 


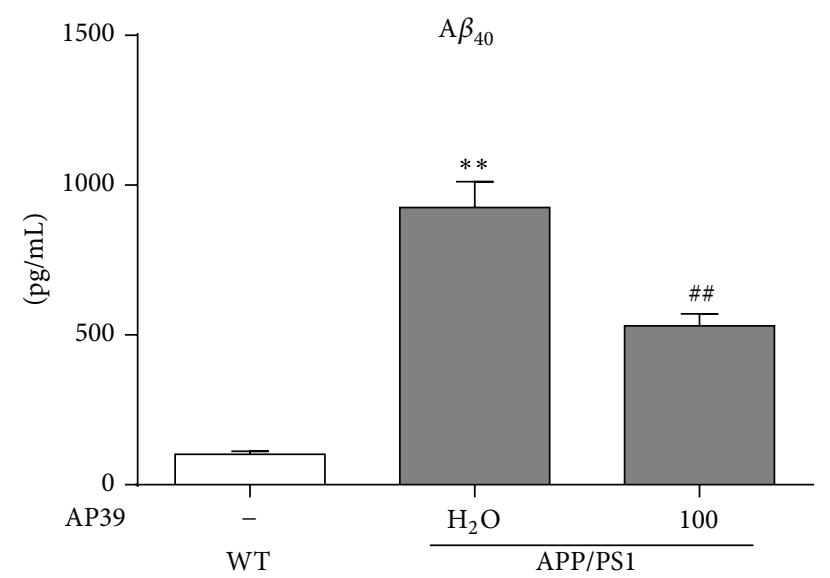

(a)

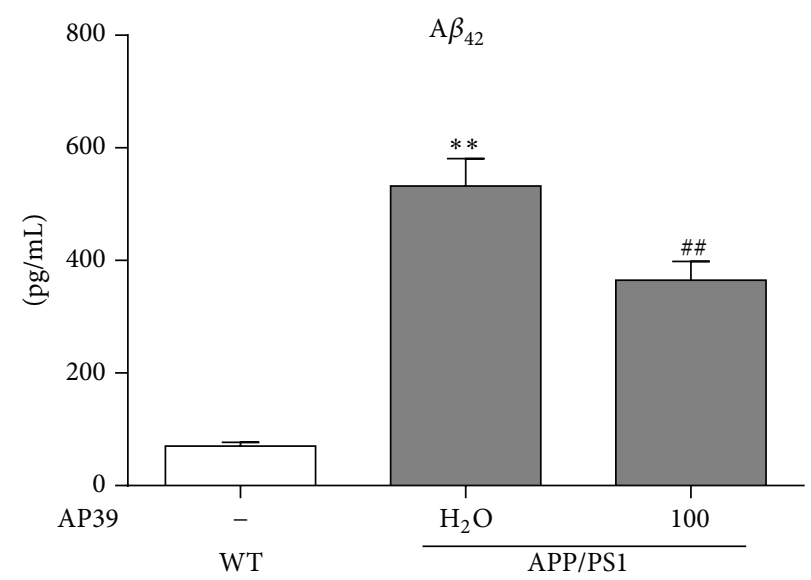

(b)
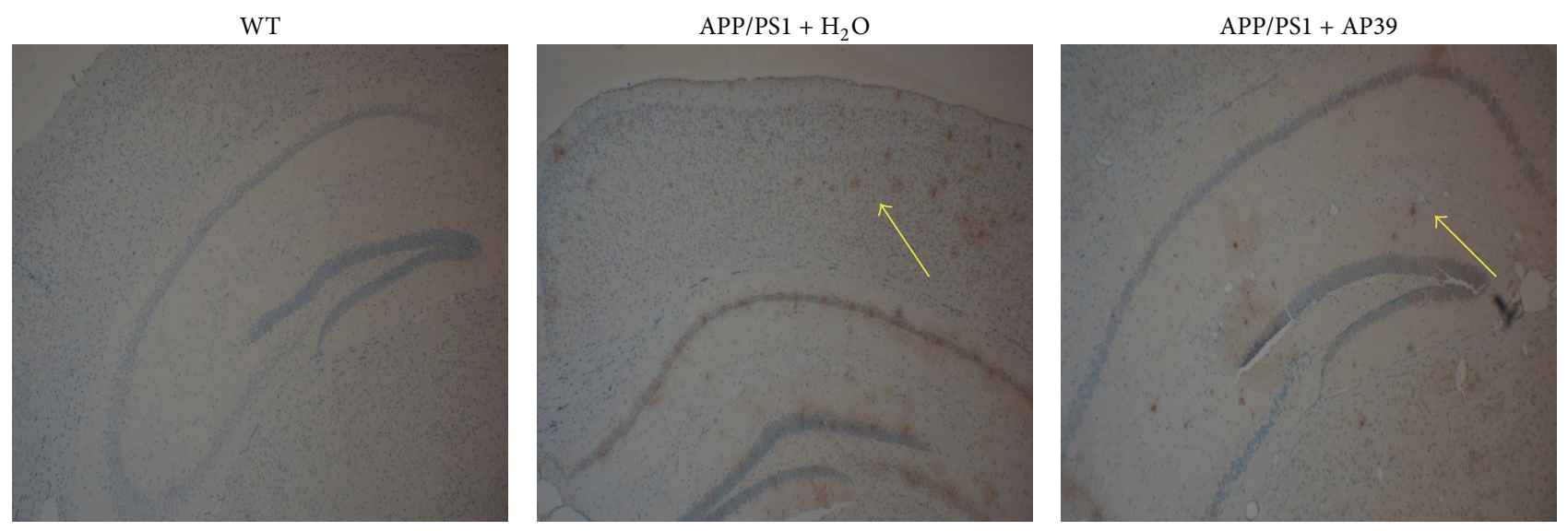

(c)

FIgURE 10: AP39 reduced A $\beta$ production and A $\beta$ deposition in APP/PS1 mice. (a)-(b) After intraperitoneal injection of AP39 for 6 weeks, $\mathrm{A} \beta_{40}$ and $\mathrm{A} \beta_{42}$ levels in the mouse brains were decreased from $925 \mathrm{pg} / \mathrm{mL}$ and $532 \mathrm{pg} / \mathrm{mL}$ to $531 \mathrm{pg} / \mathrm{mL}$ and $365 \mathrm{pg} / \mathrm{mL}$, respectively. (c) $\mathrm{A} \beta$ plaques were detected in the cortex and the hippocampus of the WT and APP/PS1 mouse brains based on 6E10 immunostaining. The statistical results show the area of the $\mathrm{A} \beta$ plaques. Original magnification: $-40 \mathrm{x}$; scale bars $=100 \mu \mathrm{m}$.

investigate this hypothesis. Our data suggest that MRI is a useful tool to observe the dynamic neuropathology changes in $\mathrm{AD}$ mouse brains and those changes in aged $\mathrm{AD}$ mice observed by MRI correlated with their cognitive dysfunction in the current study.

Interestingly, recent research has indicated that the mitochondrial translocation of $\mathrm{H}_{2} \mathrm{~S}$-producing enzymes produces an endogenous protective response to various insults [70].

In our study, AP39 served as a pharmacological tool or potential therapeutic agent that "mimics" this endogenous protective mechanism. However, some limitations of this study should be noted. First, we have not precisely determined the exact cellular metabolism of AP39. It will be necessary to conduct additional studies to establish the dynamics of the cellular metabolism of AP39 in the future. Second, the bell-shaped dose-response properties of AP39 are similar to those observed for authentic $\mathrm{H}_{2} \mathrm{~S}$ or other $\mathrm{H}_{2} \mathrm{~S}$ donors, and we must admit that there may be additional pharmacological mechanisms that may be conducive to the detected decrease in cellular bioenergetics at higher concentrations of AP39. The above limitations must be studied in future experiments.

\section{Conclusions}

Taken together, the results of the current study revealed that the main target of protection by AP39 was mitochondria based on the APP/PS1 model. We showed that AP39 exerts concentration-dependent modulatory effects on cellular bioenergetics in APP/PS1 neurons. In addition, AP39 increased ATP levels, decreased oxidative damage to mtDNA, and reduced ROS levels in APP/PS1 neurons. Moreover, AP39 regulated the balance between mitochondrial fission and fusion. All of these events contribute to an attenuation of mitochondrial dysfunction in APP/PS1 neurons. Based on these data, AP39 exerts multiple protective effects in the APP/PS1 model, including the amelioration of memory deficits, the prevention of brain atrophy, and the decrease of $\mathrm{A} \beta$ deposition. Therefore, AP39 represents a good candidate disease-modifying therapy for $\mathrm{AD}$. Despite recent advancements in our understanding of the role of AP39 in mitochondrial bioenergetics and function, whether AP39 is actually beneficial for $\mathrm{AD}$ patients remains to be determined and warrants further study. 


\section{Conflict of Interests}

The authors confirm that this paper content has no conflict of interests.

\section{Acknowledgments}

The authors thank Professor Zhang (Associate Professor, Neuroscience Center, the First Affiliated Hospital of Chongqing Medical University) for significant comments and scientific support and Professor Tang for technical assistance. This study was supported by the National Natural Science Foundation of China (Grant no. 81271222).

\section{References}

[1] Alzheimer's Association, "2015 Alzheimer's disease facts and figures," Alzheimer's \& Dementia, vol. 11, no. 3, pp. 332-384, 2015.

[2] W. S. Liang, E. M. Reiman, J. Valla et al., "Alzheimer's disease is associated with reduced expression of energy metabolism genes in posterior cingulate neurons," Proceedings of the National Academy of Sciences of the United States of America, vol. 105, no. 11, pp. 4441-4446, 2008.

[3] R. Bowser and M. A. Smith, "Cell cycle proteins in Alzheimer's disease: plenty of wheels but no cycle," Journal of Alzheimer's Disease, vol. 4, no. 3, pp. 249-254, 2002.

[4] K. Herrup, M. C. Carrillo, D. Schenk et al., "Beyond amyloid: getting real about nonamyloid targets in Alzheimer's disease," Alzheimer's \& Dementia, vol. 9, no. 4, pp. 452.el-458.el, 2013.

[5] R. H. Swerdlow and S. M. Khan, "A "mitochondrial cascade hypothesis" for sporadic Alzheimer's disease," Medical Hypotheses, vol. 63, no. 1, pp. 8-20, 2004.

[6] X. Wang, W. Wang, L. Li, G. Perry, H.-G. Lee, and X. Zhu, "Oxidative stress and mitochondrial dysfunction in Alzheimer's disease," Biochimica et Biophysica Acta-Molecular Basis of Disease, vol. 1842, no. 8, pp. 1240-1247, 2014.

[7] H. Xie, J. Guan, L. A. Borrelli, J. Xu, A. Serrano-Pozo, and B. J. Bacskai, "Mitochondrial alterations near amyloid plaques in an Alzheimer'S disease mouse model," Journal of Neuroscience, vol. 33, no. 43, pp. 17042-17051, 2013.

[8] O. Benek, L. Aitken, L. Hroch et al., "A direct interaction between mitochondrial proteins and amyloid-beta peptide and its significance for the progression and treatment of Alzheimer's disease," Current Medicinal Chemistry, In press.

[9] M. J. Calkins, M. Manczak, P. Mao, U. Shirendeb, and P. H. Reddy, "Impaired mitochondrial biogenesis, defective axonal transport of mitochondria, abnormal mitochondrial dynamics and synaptic degeneration in a mouse model of Alzheimer's disease," Human Molecular Genetics, vol. 20, no. 23, Article ID ddr381, pp. 4515-4529, 2011.

[10] S. Rosales-Corral, D. Acuna-Castroviejo, D. X. Tan et al., "Accumulation of exogenous amyloid-beta peptide in hippocampal mitochondria causes their dysfunction: a protective role for melatonin," Oxidative Medicine and Cellular Longevity, vol. 2012, Article ID 843649, 15 pages, 2012.

[11] I. Pedrós, D. Petrov, M. Allgaier et al., "Early alterations in energy metabolism in the hippocampus of APPswe/PS1dE9 mouse model of Alzheimer's disease," Biochimica et Biophysica Acta, vol. 1842, no. 9, pp. 1556-1566, 2014.
[12] A. C. Rice, P. M. Keeney, N. K. Algarzae, A. C. Ladd, R. R. Thomas, and J. P. Bennett Jr., "Mitochondrial DNA copy numbers in pyramidal neurons are decreased and mitochondrial biogenesis transcriptome signaling is disrupted in Alzheimer's disease hippocampi," Journal of Alzheimer's Disease, vol. 40, no. 2, pp. 319-330, 2014.

[13] B. Sheng, X. Wang, B. Su et al., "Impaired mitochondrial biogenesis contributes to mitochondrial dysfunction in Alzheimer's disease," Journal of Neurochemistry, vol. 120, no. 3, pp. 419-429, 2012.

[14] C. Szabõ, "Hydrogen sulphide and its therapeutic potential," Nature Reviews Drug Discovery, vol. 6, no. 11, pp. 917-935, 2007.

[15] H.-J. Wei, X. Li, and X.-Q. Tang, "Therapeutic benefits of $\mathrm{H}_{2} \mathrm{~S}$ in Alzheimer's disease," Journal of Clinical Neuroscience, vol. 21, no. 10, pp. 1665-1669, 2014.

[16] X. Q. Tang, C. T. Yang, J. Chen et al., "Effect of hydrogen sulphide on $\beta$-amyloid-induced damage in PC12 cells," Clinical and Experimental Pharmacology and Physiology, vol. 35, no. 2, pp. 180-186, 2008.

[17] A. Xuan, D. Long, J. Li et al., "Hydrogen sulfide attenuates spatial memory impairment and hippocampal neuroinflammation in beta-amyloid rat model of Alzheimer's disease," Journal of Neuroinflammation, vol. 9, article 202, 2012.

[18] K. Módis, C. Coletta, K. Erdélyi, A. Papapetropoulos, and C. Szabo, "Intramitochondrial hydrogen sulfide production by 3mercaptopyruvate sulfurtransferase maintains mitochondrial electron flow and supports cellular bioenergetics," The FASEB Journal, vol. 27, no. 2, pp. 601-611, 2013.

[19] B. Szczesny, K. Módis, K. Yanagi et al., "AP39, a novel mitochondria-targeted hydrogen sulfide donor, stimulates cellular bioenergetics, exerts cytoprotective effects and protects against the loss of mitochondrial DNA integrity in oxidatively stressed endothelial cells in vitro," Nitric Oxide, vol. 41, pp. 120130, 2014.

[20] S. Le Trionnaire, A. Perry, B. Szczesny et al., "The synthesis and functional evaluation of a mitochondria-targeted hydrogen sulfide donor, (10-oxo-10-(4-(3-thioxo-3H-1,2-dithiol-5yl)phenoxy)decyl)triphenylphosphonium bromide (AP39)," MedChemComm, vol. 5, no. 6, pp. 728-736, 2014.

[21] S. Albers, F. Inthathirath, S. K. Gill et al., "Nuclear $82-\mathrm{kDa}$ choline acetyltransferase decreases amyloidogenic APP metabolism in neurons from APP/PS1 transgenic mice," Neurobiology of Disease, vol. 69, pp. 32-42, 2014.

[22] J. L. Jankowsky, D. J. Fadale, J. Anderson et al., "Mutant presenilins specifically elevate the levels of the 42 residue $\beta$ amyloid peptide in vivo: evidence for augmentation of a 42 specific $\gamma$ secretase," Human Molecular Genetics, vol. 13, no. 2, pp. 159-170, 2004.

[23] R. Miyamoto, K.-I. Otsuguro, S. Yamaguchi, and S. Ito, "Contribution of cysteine aminotransferase and mercaptopyruvate sulfurtransferase to hydrogen sulfide production in peripheral neurons," Journal of Neurochemistry, vol. 130, no. 1, pp. 29-40, 2014.

[24] X.-Q. Tang, H.-R. Fang, C.-F. Zhou et al., "A novel mechanism of formaldehyde neurotoxicity: inhibition of hydrogen sulfide generation by promoting overproduction of nitric oxide," PLoS ONE, vol. 8, no. 1, Article ID e54829, 2013.

[25] K. Módis, C. Coletta, A. Asimakopoulou et al., "Effect of S-adenosyl-1-methionine (SAM), an allosteric activator of cystathionine- $\beta$-synthase (CBS) on colorectal cancer cell proliferation and bioenergetics in vitro," Nitric Oxide, vol. 41, pp. 146-156, 2014. 
[26] D. A. Ferrick, A. Neilson, and C. Beeson, "Advances in measuring cellular bioenergetics using extracellular flux," Drug Discovery Today, vol. 13, no. 5-6, pp. 268-274, 2008.

[27] U. Keil, A. Bonert, C. A. Marques et al., "Amyloid beta-induced changes in nitric oxide production and mitochondrial activity lead to apoptosis," The Journal of Biological Chemistry, vol. 279, no. 48, pp. 50310-50320, 2004.

[28] B. Szczesny, G. Olah, D. K. Walker et al., "Deficiency in repair of the mitochondrial genome sensitizes proliferating myoblasts to oxidative damage," PLoS ONE, vol. 8, no. 9, Article ID e75201, 2013.

[29] A. C. Kaufman, S. V. Salazar, L. T. Haas et al., "Fyn inhibition rescues established memory and synapse loss in Alzheimer mice," Annals of Neurology, vol. 77, no. 6, pp. 953-971, 2015.

[30] R. A. Bevins and J. Besheer, "Object recognition in rats and mice: a one-trial non-matching-to-sample learning task to study 'recognition memory"' Nature Protocols, vol. 1, no. 3, pp. 1306-1311, 2006.

[31] J. Zhang, Q. Cao, S. Li et al., "3-Hydroxybutyrate methyl ester as a potential drug against Alzheimer's disease via mitochondria protection mechanism," Biomaterials, vol. 34, no. 30, pp. 75527562, 2013.

[32] D.-Y. Choi, J. W. Lee, J. Peng et al., "Obovatol improves cognitive functions in animal models for Alzheimer's disease," Journal of Neurochemistry, vol. 120, no. 6, pp. 1048-1059, 2012.

[33] R. Wang, "Physiological implications of hydrogen sulfide: a whiff exploration that blossomed," Physiological Reviews, vol. 92, no. 2, pp. 791-896, 2012.

[34] C. Szabo, C. Coletta, C. Chao et al., "Tumor-derived hydrogen sulfide, produced by cystathionine- $\beta$-synthase, stimulates bioenergetics, cell proliferation, and angiogenesis in colon cancer," Proceedings of the National Academy of Sciences of the United States of America, vol. 110, no. 30, pp. 12474-12479, 2013.

[35] K. Módis, E. M. Bos, E. Calzia et al., "Regulation of mitochondrial bioenergetic function by hydrogen sulfide. Part II. Pathophysiological and therapeutic aspects," British Journal of Pharmacology, vol. 171, no. 8, pp. 2123-2146, 2014.

[36] M. Whiteman, S. Le Trionnaire, M. Chopra, B. Fox, and J. Whatmore, "Emerging role of hydrogen sulfide in health and disease: critical appraisal of biomarkers and pharmacological tools," Clinical Science, vol. 121, no. 11, pp. 459-488, 2011.

[37] L. Tomasova, M. Pavlovicova, L. Malekova et al., "Effects of AP39, a novel triphenylphosphonium derivatised anethole dithiolethione hydrogen sulfide donor, on rat haemodynamic parameters and chloride and calcium $\mathrm{Ca}_{\mathrm{v}} 3$ and RyR2 channels," Nitric Oxide, vol. 46, pp. 131-144, 2015.

[38] K. Umemura and H. Kimura, "Hydrogen sulfide enhances reducing activity in neurons: neurotrophic role of $\mathrm{H}_{2} \mathrm{~S}$ in the brain?" Antioxidants and Redox Signaling, vol. 9, no. 11, pp. 2035-2041, 2007.

[39] H. Kimura, "Physiological roles of hydrogen sulfide and polysulfides," in Chemistry, Biochemistry and Pharmacology of Hydrogen Sulfide, vol. 230 of Handbook of Experimental Pharmacology, pp. 61-81, Springer, Basel, Switzerland, 2015.

[40] N. B. Chauhan, "Effect of aged garlic extract on APP processing and tau phosphorylation in Alzheimer's transgenic model Tg2576," Journal of Ethnopharmacology, vol. 108, no. 3, pp. 385394, 2006.

[41] Q.-H. Gong, L.-L. Pan, X.-H. Liu, Q. Wang, H. Huang, and Y.Z. Zhu, "S-propargyl-cysteine (ZYZ-802), a sulphur-containing amino acid, attenuates beta-amyloid-induced cognitive deficits and pro-inflammatory response: involvement of ERK1/2 and NF-kappaB pathway in rats," Amino Acids, vol. 40, no. 2, pp. 601-610, 2011.

[42] D. Giuliani, A. Ottani, D. Zaffe et al., "Hydrogen sulfide slows down progression of experimental Alzheimer's disease by targeting multiple pathophysiological mechanisms," Neurobiology of Learning and Memory, vol. 104, pp. 82-91, 2013.

[43] X.-L. He, N. Yan, H. Zhang et al., "Hydrogen sulfide improves spatial memory impairment and decreases production of $\mathrm{A} \beta$ in APP/PS1 transgenic mice," Neurochemistry International, vol. 67, no. 1, pp. 1-8, 2014.

[44] L. Li, P. Rose, and P. K. Moore, "Hydrogen sulfide and cell signaling," Annual Review of Pharmacology and Toxicology, vol. 51, no. 1, pp. 169-187, 2011.

[45] C. Constant-Urban, M. Charif, E. Goffin et al., “Triphenylphosphonium salts of 1,2,4-benzothiadiazine 1,1-dioxides related to diazoxide targeting mitochondrial ATP-sensitive potassium channels," Bioorganic and Medicinal Chemistry Letters, vol. 23, no. 21 , pp. $5878-5881,2013$.

[46] M. Millard, J. D. Gallagher, B. Z. Olenyuk, and N. Neamati, "A selective mitochondrial-targeted chlorambucil with remarkable cytotoxicity in breast and pancreatic cancers," Journal of Medicinal Chemistry, vol. 56, no. 22, pp. 9170-9179, 2013.

[47] H. Yuan, H. Cho, H. H. Chen, M. Panagia, D. E. Sosnovik, and L. Josephson, "Fluorescent and radiolabeled triphenylphosphonium probes for imaging mitochondria," Chemical Communications, vol. 49, no. 88, pp. 10361-10363, 2013.

[48] M. Goubern, M. Andriamihaja, T. Nübel, F. Blachier, and F. Bouillaud, "Sulfide, the first inorganic substrate for human cells," The FASEB Journal, vol. 21, no. 8, pp. 1699-1706, 2007.

[49] E. Lagoutte, S. Mimoun, M. Andriamihaja, C. Chaumontet, F. Blachier, and F. Bouillaud, "Oxidation of hydrogen sulfide remains a priority in mammalian cells and causes reverse electron transfer in colonocytes," Biochimica et Biophysica Acta (BBA)—Bioenergetics, vol. 1797, no. 8, pp. 1500-1511, 2010.

[50] S. Mimoun, M. Andriamihaja, C. Chaumontet et al., "Detoxification of $\mathrm{H}_{2} \mathrm{~S}$ by differentiated colonic epithelial cells: implication of the sulfide oxidizing unit and of the cell respiratory capacity," Antioxidants and Redox Signaling, vol. 17, no. 1, pp. 110, 2012.

[51] M. Groeger, J. Matallo, O. McCook et al., “Temperature and celltype dependency of sulfide effects on mitochondrial respiration," Shock, vol. 38, no. 4, pp. 367-374, 2012.

[52] H. Aslami, M. J. Schultz, and N. P. Juffermans, "Potential applications of hydrogen sulfide-induced suspended animation," Current Medicinal Chemistry, vol. 16, no. 10, pp. 1295-1303, 2009.

[53] P. Nicholls, "Inhibition of cytochrome c oxidase by sulphide," Biochemical Society Transactions, vol. 3, no. 2, pp. 316-319, 1975.

[54] A. A. Khan, M. M. Schuler, M. G. Prior et al., "Effects of hydrogen sulfide exposure on lung mitochondrial respiratory chain enzymes in rats," Toxicology and Applied Pharmacology, vol. 103, no. 3, pp. 482-490, 1990.

[55] C. Sturchler-Pierrat, D. Abramowski, M. Duke et al., "Two amyloid precursor protein transgenic mouse models with Alzheimer disease-like pathology," Proceedings of the National Academy of Sciences of the United States of America, vol. 94, no. 24, pp. 13287-13292, 1997.

[56] Z. Qiu, D. L. Naten, J. C. Liston, J. Yess, and G. W. Rebeck, “A novel approach for studying endogenous abeta processing using cultured primary neurons isolated from APP transgenic mice," Experimental Neurology, vol. 170, no. 1, pp. 186-194, 2001. 
[57] S. Bürger, Y. Yafai, M. Bigl, P. Wiedemann, and R. Schliebs, "Effect of VEGF and its receptor antagonist SU-5416, an inhibitor of angiogenesis, on processing of the $\beta$-amyloid precursor protein in primary neuronal cells derived from brain tissue of Tg2576 mice," International Journal of Developmental Neuroscience, vol. 28, no. 7, pp. 597-604, 2010.

[58] R. H. Takahashi, C. G. Almeida, P. F. Kearney et al., "Oligomerization of Alzheimer's beta-amyloid within processes and synapses of cultured neurons and brain," Journal of Neuroscience, vol. 24, no. 14, pp. 3592-3599, 2004.

[59] M.-H. Wu and C.-Y. Kuo, "Application of high throughput perfusion micro 3-D cell culture platform for the precise study of cellular responses to extracellular conditions-effect of serum concentrations on the physiology of articular chondrocytes," Biomedical Microdevices, vol. 13, no. 1, pp. 131-141, 2011.

[60] G. J. Tranah, J. S. Yokoyama, S. M. Katzman et al., "Mitochondrial DNA sequence associations with dementia and amyloidbeta in elderly African Americans," Neurobiology of Aging, vol. 35, no. 2, pp. 442.el-442.e8, 2014.

[61] M. P. Mattson, "Mother's legacy: mitochondrial DNA mutations and Alzheimer's disease," Trends in Neurosciences, vol. 20, no. 9, pp. 373-375, 1997.

[62] X. Wang, B. Su, H.-G. Lee et al., "Impaired balance of mitochondrial fission and fusion in Alzheimer's disease," The Journal of Neuroscience, vol. 29, no. 28, pp. 9090-9103, 2009.

[63] P. H. Reddy, "Amyloid beta, mitochondrial structural and functional dynamics in Alzheimer's disease," Experimental Neurology, vol. 218, no. 2, pp. 286-292, 2009.

[64] M. Cagalinec, D. Safiulina, M. Liiv et al., "Principles of the mitochondrial fusion and fission cycle in neurons," Journal of Cell Science, vol. 126, no. 10, pp. 2187-2197, 2013.

[65] M. R. Brier, J. B. Thomas, A. Z. Snyder et al., "Loss of intranetwork and internetwork resting state functional connections with Alzheimer's disease progression," Journal of Neuroscience, vol. 32, no. 26, pp. 8890-8899, 2012.

[66] M. J. de Leon, S. Desanti, R. Zinkowski et al., "MRI and CSF studies in the early diagnosis of Alzheimer's disease," Journal of Internal Medicine, vol. 256, no. 3, pp. 205-223, 2004.

[67] J. Yin, G. H. Turner, S. W. Coons, M. Maalouf, E. M. Reiman, and J. Shi, "Association of amyloid burden, brain atrophy and memory deficits in aged apolipoprotein $\varepsilon 4$ mice," Current Alzheimer Research, vol. 11, no. 3, pp. 283-290, 2014.

[68] T. M. Wengenack, C. R. Jack Jr., M. Garwood, and J. F. Poduslo, "MR Microimaging of amyloid plaques in Alzheimer's disease transgenic mice," European Journal of Nuclear Medicine and Molecular Imaging, vol. 35, supplement 1, pp. S82-S88, 2008.

[69] Y. Mu and F. H. Gage, "Adult hippocampal neurogenesis and its role in Alzheimer's disease," Molecular Neurodegeneration, vol. 6, article 85, 2011.

[70] H. Teng, B. Wu, K. Zhao, G. Yang, L. Wu, and R. Wang, "Oxygen-sensitive mitochondrial accumulation of cystathionine $\beta$-synthase mediated by Lon protease," Proceedings of the National Academy of Sciences of the United States of America, vol. 110, no. 31, pp. 12679-12684, 2013. 


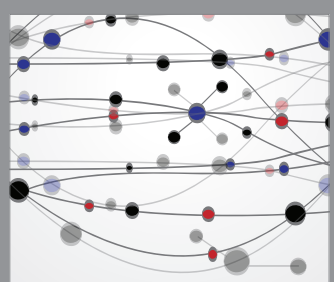

The Scientific World Journal
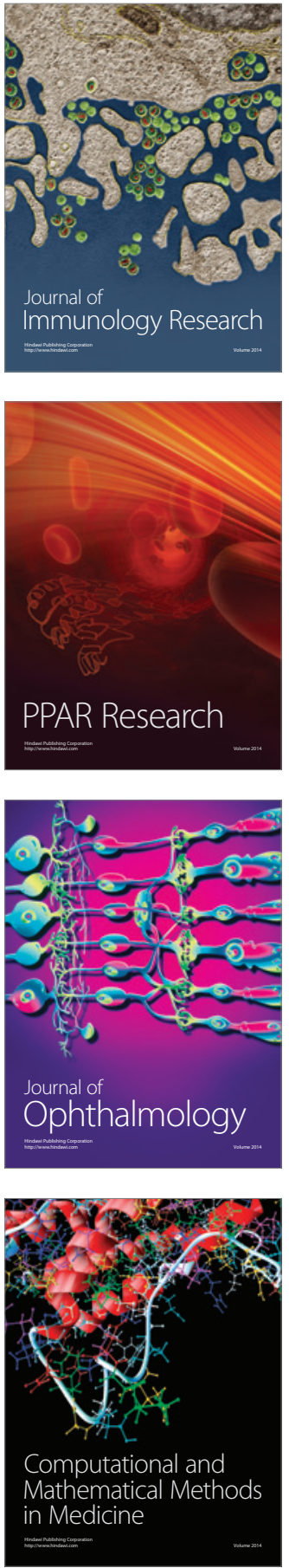

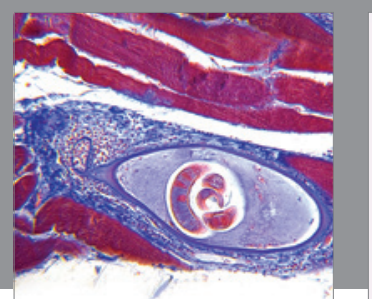

Gastroenterology Research and Practice

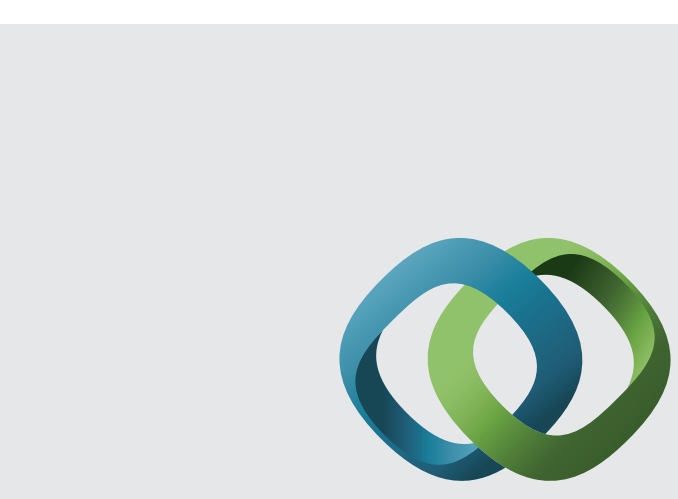

\section{Hindawi}

Submit your manuscripts at

http://www.hindawi.com
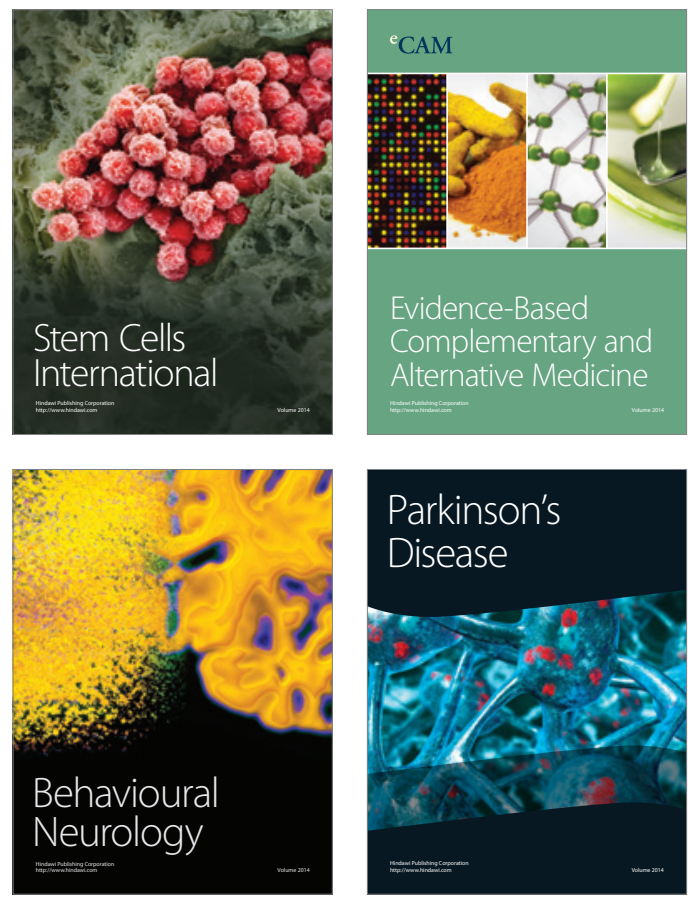
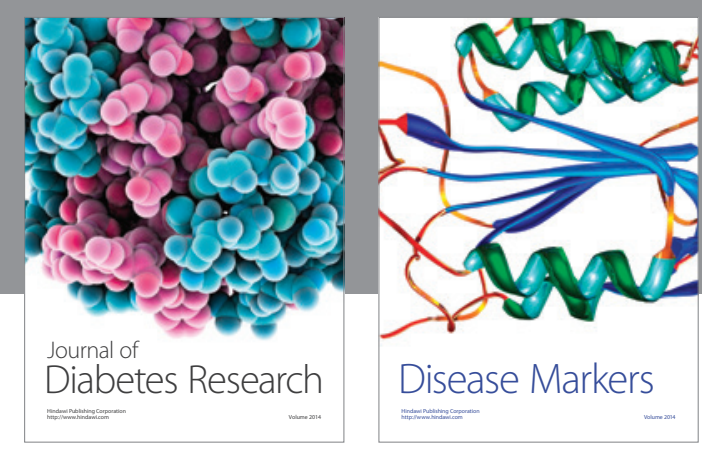

Disease Markers
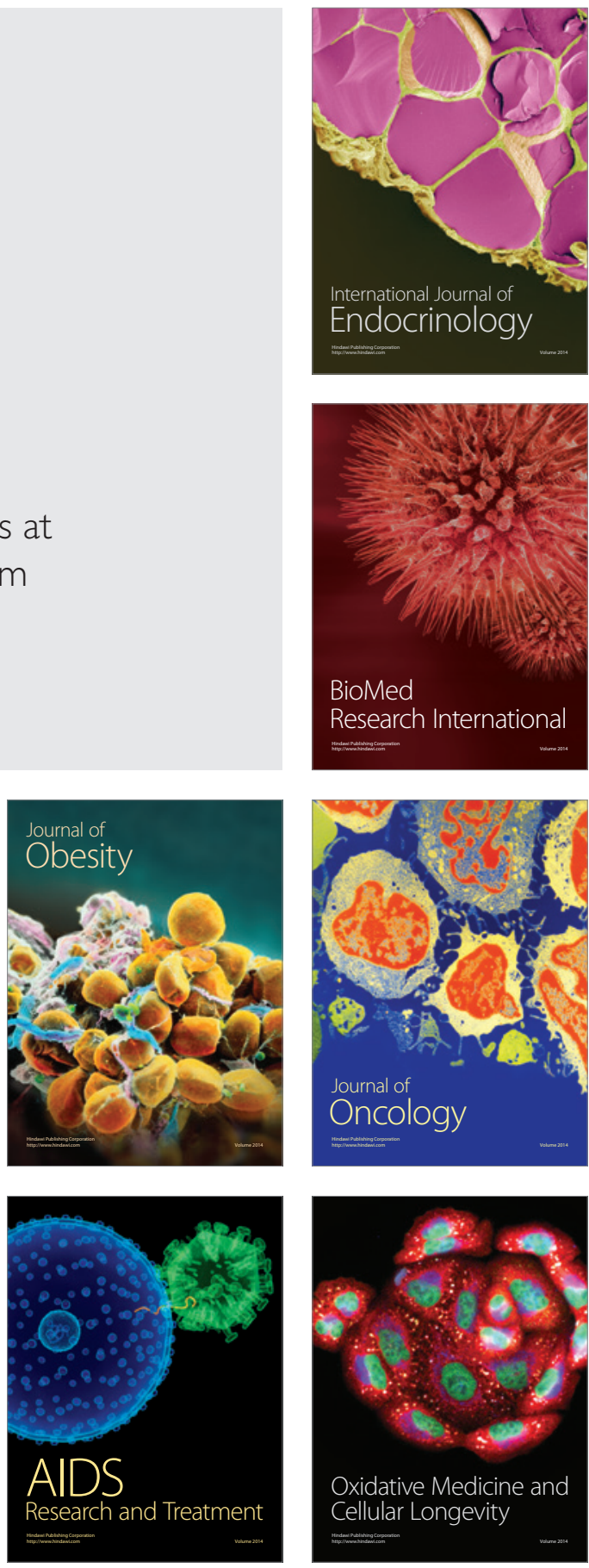